\title{
Human Natural Anti-Gal IgG Regulates Alternative Complement Pathway Activation on Bacterial Surfaces
}

\author{
Randa M. Hamadeh, ${ }^{\star \star}$ Gary A. Jarvis, ${ }^{\star \star}$ Uri Galili, ${ }^{\star *}$ Robert E. Mandrell,* Ping Zhou, ${ }^{\star}$ and J. McLeod Griffiss** \\ ${ }^{*}$ Center for Immunochemistry, Veterans Administration Medical Center, San Francisco, California 94121; \\ and ${ }^{\ddagger}$ University of California San Francisco, San Francisco, California 94143
}

\begin{abstract}
One percent of circulating IgG in humans recognizes galactose $\alpha 1,3$ galactose residues (anti-Gal) and is synthesized in response to stimulation by enteric bacteria. In this study, we found that the prevalence of binding of anti-Gal to blood isolates is significantly higher than its binding to normal stool isolates. When anti-Gal bound onto the lipopolysaccharide of a representative blood isolate, Serratia marcescens \#21, it blocked its alternative complement pathway (ACP) lysis and made the organism serum resistant. In contrast, when anti-Gal bound to the capsular polysaccharide of a serum sensitive Serratia, \#7, it increased ACP killing of this strain. The mechanism of blockade of ACP lysis by anti-Gal did not involve a decrease in the number of $\mathrm{C} 3$ molecules deposited onto Serratia \#21 or an inhibition of the binding of C3b to its LPS, nor did it change the iC $3 \mathrm{~b}$ and $\mathrm{C} 3 \mathrm{~d}$ degradation products of bound $\mathrm{C} 3 \mathrm{~b}$ or prevent membrane attack complex formation on this organism. Our findings suggest that the effect of anti-Gal on immune lysis is dependent on the bacterial outer membrane structure to which it binds. We postulate that anti-Gal may play a role in the survival of selected Enterobacteriacae in Gram-negative sepsis by blocking ACP-mediated lysis of such bacteria by the nonimmune host, and that this effect depends on where antiGal finds its epitope on the bacterial outer membrane. (J. Clin. Invest. 1992. 89:1223-1235.) Key words: anti-Gal • alternative complement pathway $\bullet$ sepsis
\end{abstract}

\section{Introduction}

Anti-Gal is a natural polyclonal IgG antibody found in the serum of all humans (1). It constitutes as much as $1 \%$ of the total circulating serum IgG (1) and binds specifically to glycoconjugates bearing $\alpha 1,3$ terminal digalactose residues (2). $\mathrm{Hu}$ man cells do not express the Gal $\alpha 1,3 \mathrm{Gal}$ structure on their surface (3). However, this epitope has been found on surface glycoconjugates of a number of mammalian cells including mouse $(4,5)$, rabbit $(6)$, and cow (7) cells. Studies of the distribution of anti-Gal and the Gal $\alpha 1,3 \mathrm{Gal}$ epitope among primates reveals a reciprocal evolutionary pattern $(8,9)$. Old World monkeys, apes, and humans have suppressed expression of the $\mathrm{Gal} \alpha 1,3 \mathrm{Gal}$ structure, concomitant with the production

This is paper No. 47 from the Center for Immunochemistry of the University of California at San Francisco.

Address correspondence to Randa M. Hamadeh, M. D., Veterans Administration Medical Center/113A, 4150 Clement Street, San Francisco, CA 94121.

Received for publication 27 February 1991 and in revised form 3 December 1991.

The Journal of Clinical Investigation, Inc.

Volume 89, April 1992, 1223-1235 of anti-Gal. Nonprimate mammals, prosimians, and New World monkeys express this epitope but do not synthesize antiGal. Neither the evolutionary pressure that selected Old World primates, including man, for the synthesis of anti-Gal nor the present survival advantage to maintaining this antibody in such high titers is known.

The presence throughout life of anti-Gal in high titers in serum led to the hypothesis that bacteria within the normal intestinal flora provide a constant antigenic stimulation for the synthesis of anti-Gal. This would be analogous with the bacterial stimulus for synthesis of blood group antibodies (10). Indeed, we found that anti-Gal did bind to a number of Escherichia coli, Klebsiella, and Salmonella strains (11). Some of these bacteria had been isolated from the bloodstreams of patients and we subsequently found that anti-Gal often bound to Gram-negative human blood isolates. These findings raised intriguing questions about how these organisms could survive in the bloodstream in the presence of such high titers of specific antibody.

In this study, we determined the prevalence of binding of anti-Gal to human blood isolates and compared it to that to normal stool isolates. We then examined the effect on the deposition and degradation of complement components onto two representative Serratia marcescens blood isolates of anti-Gal binding to their surfaces. The two bacteria bound anti-Gal but differed in their sensitivity to killing by normal human serum (NHS) ${ }^{1}$. We report that bloodstream isolates are significantly more apt to bind anti-Gal than isolates of the same species from the stools of laboratory volunteers, that anti-Gal does not provide a "protected" site to which $\mathrm{C} 3$ can bind, and that when anti-Gal binds to LPS sites, it blocks immune lysis that is activated through the alternative complement pathway (ACP) and makes the organisms serum resistant (Ser'). We hypothesize that the blockade of complement-mediated clearance mechanisms by the binding of anti-Gal to their surfaces may allow some bacteria to survive in the bloodstreams of patients with sepsis.

\section{Methods}

Bacterial strains and antigens. We studied 90 blood isolates from patients with Gram-negative sepsis who were hospitalized at the Beth Israel (BI) Hospital in Boston, Massachusetts and the Veterans Administration Medical Center (SF VAMC) in San Francisco, California, and

1. Abbreviations used in this paper: $\mathrm{A}_{640}$, absorbance at wavelength 640; ACP, alternative complement pathway; BI, Beth Israel; CP, classical pathway; $\mathrm{GAL}^{-}-\mathrm{NHS}$, NHS depleted of anti-Gal; $\mathrm{K}$, capsular polysaccharide; MAC, membrane attack complex; M-H, Mueller-Hinton; NHS, normal human serum; $\mathrm{P}^{-}$, properdin deficient; RRBCs, rabbit red blood cells; RT, room temperature; Ser', serum resistant; Sers, serum sensitive; SF VAMC, San Francisco Veterans Administration Medical Center; VBS, veronal-buffered saline; $\mathrm{VBS}^{++}$, VBS containing $1 \mathrm{mM} \mathrm{MgCl} 2$ and $0.15 \mathrm{mM} \mathrm{CaCl}_{2}$. 
27 Gram-negative facultatively aerobic bacteria isolated from the stools of healthy volunteers from our laboratory in San Francisco. 44 isolates were collected consecutively from blood cultures submitted from July, 1987 through June, 1988 to the SF VAMC Clinical Laboratory and represented all such isolates of which we are aware. An additional blood isolate from the VAMC, S. marcescens \#7, has been extensively characterized (12). The remaining strains were selected randomly from a collection of all blood isolates from the BI Clinical Laboratory during 13 consecutive months from May, 1981 to May, 1982 , inclusive. We already have characterized $S$. marcescens \#21 from the BI collection (12).

LPS and capsular polysaccharides (K) were extracted from Serratia \#21 and \#7 following established methods (12-14).

Purification of anti-Gal. Anti-Gal was isolated by affinity chromatography from plasma of healthy individuals with blood type $A B$, as described previously (15). Batches of $50 \mathrm{ml}$ of heat-inactivated plasma were loaded onto a 20-ml affinity chromatography SYNSORB column to which the oligosaccharide epitope $\mathrm{Gal} \alpha 1,3 \mathrm{Gal} \beta 1,4 \mathrm{GlcNAc}$ (Chembiomed Ltd., Edmonton, Alberta, Canada) had been conjugated. After extensive washing with PBS, the column-bound antibodies were eluted with $0.5 \mathrm{M}$ melibiose (Sigma Chemical Co., St. Louis, MO) in PBS and dialyzed against PBS. The final anti-Gal concentration was brought to $100 \mu \mathrm{g} / \mathrm{ml}$, a concentration equivalent to that in NHS (15). Serum anti-Gal is normally exclusively IgG (16); we confirmed that the eluted antibody was IgG by radial immunodiffusion (Behring, Marburg, FRG). The reactivity of the purified anti-Gal was assessed as described previously (1) by testing the ability of this IgG to agglutinate rabbit red blood cells (RRBCs) that express abundant $\alpha$-galactosyl residues on their surface.

Preparation of anti-Gal depleted NHS ( $\left.\mathrm{Gal}^{-} \mathrm{NHS}\right)$. NHS was depleted of anti-Gal ( $\mathrm{Gal}^{-} \mathrm{NHS}$ ) by passing it repeatedly through the SYNSORB column. This was done with fresh NHS and at $4^{\circ} \mathrm{C}$ to preserve complement activity. The anti-Gal-depleted serum lost $10 \%$ of normal ACP hemolytic activity (17). Gal- NHS lost its ability to agglutinate RRBCs (1).

Dot blot assay. This assay was performed as described by our laboratory (18). Briefly, we dotted organisms grown on Mueller-Hinton (MH) agar onto pieces of nitrocellulose paper, which were then air dried. We then incubated the nitrocellulose, first in a $1 \%$ casein solution for $30 \mathrm{~min}$ and then with anti-Gal $(2 \mu \mathrm{g} / \mathrm{ml}$ in casein solution) for $2 \mathrm{~h}$. Papers were washed with PBS and reacted for $1 \mathrm{~h}$ with an alkaline phosphatase-conjugated goat anti-human IgG (Vector Laboratories, Burlingame, California), as secondary antibody. The blots were then developed with a substrate solution that contained naphthol $(1 \mathrm{mg} / \mathrm{ml})$ and Fast Red TR salt ( $2 \mathrm{mg} / \mathrm{ml}$ ) (Sigma Chemical Co.) in $50 \mathrm{mM}$ Tris buffer $(\mathrm{pH}=8)$. Control blots were included that had on them only: $(a)$ M-H agar without bacteria; $(b)$ bacteria and secondary antibody but no anti-Gal; and $(c)$ alkaline phosphatase substrate but no antibody. We repeated the assay three times for each organism and recorded the results as positive when a red color was clearly visible as compared with controls, and this result occurred in at least two of the three assays. Two independent observers recorded the results.

Bactericidal assay. We used a standard bactericidal assay (19). Serratia \#21 and \#7 were grown overnight on Mueller-Hinton agar, transferred to a flask containing M-H broth, and incubated at $37^{\circ} \mathrm{C}$ in a shaking water bath. When the cultures had reached an absorbance at wavelength $640\left(\mathrm{~A}_{640}\right)$ of 0.6 , the bacteria were pelleted and resuspended to an $\mathrm{A}_{640}$ of 0.6 in either veronal-buffered saline (VBS) with $0.5 \% \mathrm{BSA}$ or VBS containing $1 \mathrm{mM} \mathrm{MgCl}_{2}$ and $0.15 \mathrm{mM} \mathrm{CaCl}$ $\left(\mathrm{VBS}^{++}\right.$) with $0.5 \%$ BSA. They were then diluted $1: 35,000$ in the same buffer. This dilution of bacteria had $\sim 10^{4} \mathrm{CFU} / \mathrm{ml}$. Reaction mixtures were prepared by combining equal volumes of the diluted bacterial suspension and a test serum that contained intact complement systems. We tested the following sera: (a) aliquots of NHS; $(b) \mathrm{Gal}^{-}$ NHS; (c) hypogammaglobulinemic serum (hypor serum) that contained $<10 \%$ of normal immunoglobulin levels and, in particular, $<5-10 \%$ of normal anti-Gal levels; $(d)$ serum obtained from a patient with congenital properdin deficiency $\left(\mathrm{P}^{-}\right.$serum $)$that had no measurable ACP activity (20); $(e) \mathrm{P}^{-}$serum absorbed at $0^{\circ} \mathrm{C}$ with the test strain for three sequential 30 -min periods. These absorptions were performed by resuspending the organism to an $\mathrm{A}_{640}$ of 1 and pelleting it. Serum was then added in a volume equal to twice the bacterial pellet (serum:bacterial pellet ratio $=2$ ).

When the effect of anti-Gal was being assessed, anti-Gal $(100 \mu \mathrm{g} /$ $\mathrm{ml}$ ) was added to the reaction mixture in a volume equal to that of the test serum. In experiments that assessed the inhibitory effects of carbohydrates, anti-Gal $(100 \mu \mathrm{g} / \mathrm{ml})$ and the inhibitor, either $\alpha$ methyl galactoside, lactose, or sucrose, at $0.1 \mathrm{M}$ final concentrations, were simultaneously added to the reaction mixture in equal volumes to the test serum.

In some assays, the test serum was chelated with $10 \mathrm{mM}$ EGTA containing $10 \mathrm{mM} \mathrm{MgCl}{ }_{2}$ (MgEGTA) to block activation of the classical complement pathway while allowing alternative pathway activation to proceed. VBS instead of $\mathrm{VBS}^{++}$was used in these assays.

In all these experiments, sufficient VBS or $\mathrm{VBS}^{++}$was added to each reaction mixture to bring the final reaction mixture volume to 125 $\mu l$. The final serum concentration was $20 \%$ unless indicated otherwise.

The reaction mixtures were incubated for $1 \mathrm{~h}$ at $37^{\circ} \mathrm{C}$ in a shaking water bath. We then plated $20 \mu \mathrm{l}$ from each reaction mixture onto $\mathrm{M}-\mathrm{H}$ agar. Colonies of surviving organisms were counted after $18 \mathrm{~h}$ incubation at $37^{\circ} \mathrm{C}$. We calculated bactericidal activity by comparing the number of survivors in reaction mixtures containing active serum (intact complement source) to those in mixtures containing heat-inactivated serum (absence of active complement). Each assay was repeated at least 10 times.

Binding of anti-Gal to $S$. marcescens \#21 and \#7 whole organisms. We examined the binding of anti-Gal to the Serratia blood isolates, \#21 and \#7. Purified anti-Gal was radiolabeled to a sp act of $1.85 \times 10^{5}$ $\mathrm{cpm} / \mu \mathrm{g}$ by the lactoperoxidase-iodination procedure (21). Serratia $\# 21$ and \#7 were grown for $24 \mathrm{~h}$ on $\mathrm{M}-\mathrm{H}$ agar, and then suspended to an $\mathrm{A}_{640}$ of 0.6 in PBS. Aliquots of $100 \mu \mathrm{l}$ of this suspension were put in microfuge tubes, and the bacteria collected and washed with PBS by centrifugation. We then added either 12,120 , or $390 \mu \mathrm{g}$ of ${ }^{125} \mathrm{I}-$ anti-Gal to each tube and incubated the mixture for 60 minutes at $37^{\circ} \mathrm{C}$. The organisms were washed by repeated centrifugation in PBS and radiolabeled bound anti-Gal was counted in a gamma counter. We determined the number of $\mathrm{CFU} / \mathrm{ml}$ for each test organism and calculated the number of molecules of ${ }^{125} \mathrm{I}$-anti-Gal bound per CFU at saturation.

To assess the specificity of the binding, we added a 50-fold excess of cold anti-Gal to duplicate reaction mixtures of organisms incubated with $12 \mu \mathrm{g}$ of ${ }^{125} \mathrm{I}$-anti-Gal and determined the percentages of radioactivity that were displaced.

$S D S-P A G E$ and immunoblots. Lysates and proteinase K-treated lysates of $S$. marcescens \#21 and \#7 were prepared as outlined by Hitchcock and Brown (22); dissolved in 2\% SDS; applied to discontinuous slab gels (3\% acrylamide spacer gel, $13 \%$ resolving gel) and electrophoresed at $10 \mathrm{~mA}$ current for 4-5 h (SDS-PAGE) (23). The electroblotted samples were then transferred to nitrocellulose with the use of the Western blot transfer method of Burnette (24). We first incubated the transblots for $30 \mathrm{~min}$ in a $1 \%$ casein solution to block nonspecific binding and then placed them for $1 \mathrm{~h}$ in a $1 \mu \mathrm{g} / \mathrm{ml}$ solution of anti-Gal in $1 \%$ casein. The nitrocellulose paper was then washed and incubated for $1 \mathrm{~h}$ with a 1:500 solution in $1 \%$ casein of an alkaline phosphatase-conjugated goat anti-human IgG (Vector Laboratories, Burlingame, CA). A naphthol substrate $(1 \mathrm{mg} / \mathrm{ml})$ and Fast Red solution $(2 \mathrm{mg} / \mathrm{ml})$ (Sigma Chemical Co.) in $50 \mathrm{mM}$ Tris buffer $(\mathrm{pH}=8)$ were then added and the development of a pink color assessed visually. For time course experiments, lysates and proteinase $\mathrm{K}$-treated lysates of organisms grown in Mueller-Hinton broth for 3, 6, 12, and $24 \mathrm{~h}$ were prepared and examined as outlined above. As control reactions, we included transblots that were incubated with goat anti-human IgG alone (no anti-Gal). To assess the specificity of the anti-Gal binding to these lysates, we incubated transblots with $\mathrm{Gal}^{-}$serum as the blocking agent in place of casein, followed with biotinylated anti-Gal $(20 \mu \mathrm{g} / \mathrm{ml})$ 
(25) and then avidin linked to alkaline phosphatase (as per Vector Laboratories). The blots were visualized as outlined above.

To examine whether anti-Gal is the major antibody in our test NHS that is specific for Serratia \#21 LPS, we blotted this LPS with either $10 \%$ NHS or $10 \% \mathrm{Gal}^{-}$NHS in $1 \%$ casein and then proceeded with incubations with goat anti-human IgG and then substrate solutions as outlined above.

Enzyme-linked immunosorbent assay. We used an ELISA to estimate anti-Gal binding to LPS and purified capsular polysaccharides. Briefly, we used $75 \mu \mathrm{l}$ of a $50-\mu \mathrm{g} / \mathrm{ml}$ solution of the capsular polysaccharides to sensitize the wells of a microtiter plate that had been previously coated with a $1 \mathrm{mg} / \mathrm{ml}$ solution of poly-L-lysine $\left(47,000 M_{\mathrm{r}}\right)$ (Sigma Chemical Co.). Nonspecific binding was blocked by $0.1 \%$ BSA in PBS with $0.02 \%$ sodium azide. Wells were then incubated for $1 \mathrm{~h}$ with serial twofold dilutions of a $100-\mu \mathrm{g} / \mathrm{ml}$ anti-Gal solution. After washing, $75 \mu \mathrm{l}$ of a 1:500 solution of alkaline phosphatase-labeled goat anti-human IgG (Vector Laboratories) were placed in each well and allowed to react for $1 \mathrm{~h}$. The wells were then washed extensively and a $p$-nitrophenyl phosphate disodium substrate was added $(2 \mathrm{mg} / \mathrm{ml}$ in $100 \mathrm{mM}$ sodium bicarbonate, $10 \mathrm{mM} \mathrm{MgCl}_{2}$, $\mathrm{pH}$ 9.5) (Sigma Chemical Co.). The absorbance of the solution in the plates after $15 \mathrm{~min}$ of incubation with the substrate was read with a $405-\mathrm{nm}$ filter on an ELISA reader (2550; Bio-Rad Laboratories, Richmond, CA). The LPS ELISA was done in essentially the same way, except that the wells of the microtiter plates were not precoated with poly-L-lysine and that $75 \mu \mathrm{l}$ of a $50-\mu \mathrm{g} / \mathrm{ml}$ solution of \#21 LPS sensitized these wells.

To examine the specificity of anti-Gal binding the same experiment was done using $\mathrm{Gal}^{-}$as the blocking agent (instead of $0.1 \% \mathrm{BSA}$ ) followed by incubation with serial twofold dilutions of a biotinylated antiGal solution $(100 \mu \mathrm{g} / \mathrm{ml})(25)$, and then with avidin linked to alkaline phosphatase (as per Vector Laboratories). The reaction was read as outlined above.

To find out whether anti-Gal bound to the same antigenic determinants in LPS and $\mathrm{K}$ antigen, we absorbed anti-Gal at $0^{\circ} \mathrm{C}$ for three sequential 30-min periods with $S$. marcescens $\# 7$ (K antigen binding) or $S$. marcescens $\# 21$ (LPS antigen binding). To do that, the organisms were resuspended in PBS to an $\mathrm{A}_{640}$ of 1 and then pelleted. Anti-Gal $(100 \mu \mathrm{g} / \mathrm{ml})$ was then added in a volume equal to twice that of the bacterial pellet and the ability of each absorbed anti-Gal preparation to bind $S$. marcescens $\# 7 \mathrm{~K}$ antigen and \#21 LPS was then tested in an ELISA.

C3 purification and deposition. C3 was isolated from human plasma as described by Hammer et al. (26) and was further purified as described by our laboratory (27). C3 was radiolabeled using iodobeads (Pierce Chemical Co., Rockford, IL) as recommended by the manufacturer. Radiolabeling of the $\mathrm{C} 3$ decreased its hemolytic activity by $<10$ $30 \%$ (depending on the experiment) as assessed by the method of Hostetter et al. (28). C3 concentration was determined by the Pierce protein assay as recommended by the manufacturer.

C3 deposition was determined as previously described (27). Briefly, $1 \mathrm{ml}$ of strain \#21 or \#7 at $10^{8}-10^{9} \mathrm{CFU} / \mathrm{ml}$ in VBS was pelleted, suspended in $200 \mu \mathrm{l}$ of anti-Gal $100 \mu \mathrm{g} / \mathrm{ml}$ solution in PBS (NHS concentration) or in $200 \mu \mathrm{l}$ of PBS without anti-Gal, and incubated at room temperature for $30 \mathrm{~min}$. The bacteria were then pelleted and washed three times with PBS. Serum (hypor or Gal ${ }^{-}$) or heat inactivated serum containing ${ }^{125} \mathrm{I}$-labeled $\mathrm{C} 3$ (sp act $1.22 \times 10^{5}$ for experiments with $\mathrm{Gal}^{-}$serum and $1.5 \times 10^{6}$ for experiments with hypo $\gamma$ serum) at a ratio of 1:44 labeled to unlabeled $C 3$ was added to the bacterial pellet to effect a $20 \%$ final serum concentration in a total vol of $500 \mu \mathrm{l}$ and the mixture was incubated for $1 \mathrm{~h}$ at $37^{\circ} \mathrm{C}$. Aliquots $\left(10^{8}\right.$ $\mathrm{CFU}$ ) were layered onto $1 \mathrm{ml}$ of $10 \% \mathrm{BSA}$ and the bacteria were then pelleted at $12,500 \mathrm{~g}$, and washed in PBS three times. The tube tips were cut and counted in a gamma scintillation counter. All assays were performed at least twice.

Effect of anti-Gal on the deposition of $C 3$ and $C 9$ on Serratia \#21 LPS. Purified LPS from Serratia \#21 was separated by SDS-PAGE and blotted onto nitrocellulose as previously described. The transblot was then incubated with $10 \%$ hypo $\gamma$ serum (in $1 \%$ casein), $10 \%$ hypo $\gamma$ serum + anti-Gal $(100 \mu \mathrm{g} / \mathrm{ml})$, or $10 \%$ heat-inactivated hypo $\gamma$ serum for $1 \mathrm{~h}$ at room temperature (RT). The hypo $\gamma$ serum had normal complement activity and no antibodies against \#21 LPS. The transblot was then washed extensively in PBS and incubated for $1 \mathrm{~h}$ at RT in a 1:100 dilution in $1 \%$ casein of affinity-purified alkaline phosphatase-linked goat anti-human C3 or C9 (E-Y Laboratories, Inc., San Mateo, CA). The transblots then were developed as outlined previously. Control reactions with only secondary antibody (and no hypo $\gamma$ serum) and with heat-inactivated hypo $\gamma$ serum (see above) were included.

To further assess the binding sites for anti-Gal and for C 3 on Serratia \#21 LPS, we tested the ability of anti-Gal to find its cognitive epitope on \#21 LPS after C3 had bound to this antigen. The transblot of Serratia \#21 LPS was first incubated with 10\% hypo $\gamma$ serum for $1 \mathrm{~h}$, washed extensively with PBS, then incubated with anti-Gal $(100 \mu \mathrm{g} / \mathrm{ml}$ in $1 \%$ casein) for $2 \mathrm{~h}$, and finally incubated with goat anti-human IgG and developed as outlined above.

Molecular form of the bound C3 fragments. C3 deposition onto Serratia \#21 and \#7 by hypo $\gamma$ serum with or without anti-Gal or heatinactivated hypo $\gamma$ serum with or without anti-Gal was done as outlined above, with the exception that no radiolabeled $\mathrm{C} 3$ was added to the serum. The $\mathrm{C} 3$ fragments were eluted from the organisms by treating them with $1 \mathrm{M}$ hydroxylamine in $0.2 \mathrm{M} \mathrm{NaHCO}_{3}$ containing $0.1 \%$ SDS $(\mathrm{pH}=10.0)$ for $60 \mathrm{~min}$ at $37^{\circ} \mathrm{C}(29)$. The bacteria were removed by centrifugation, and the supernatant fluid containing the eluted fragments was evaluated under reducing conditions by SDS-PAGE with $10 \%$ polyacrylamide gels and transferred to nitrocellulose following methods outlined previously in this section. Native $\mathrm{C} 3$ was run along with these samples in order to evaluate the nature of the fragments obtained. The transblot was then incubated serially in a $1 \%$ casein solution for $30 \mathrm{~min}$, then in a 1:100 solution in $1 \%$ casein of affinity purified goat anti-human C3 linked to alkaline phosphatase (E-Y Laboratories, Inc.) for $1 \mathrm{~h}$ at RT, washed three times with PBS, and developed as previously outlined. In addition, duplicate transblots containing identical samples to the ones above were prepared and were incubated with goat anti-human C3d linked to alkaline phosphatase (The Binding Site, San Diego, CA), in order to further evaluate the identity of the bands obtained.

C9 deposition on Serratia \#21 in the presence and absence of anti$\mathrm{Gal}$. We followed the whole cell ELISA method detailed by Schlesinger et al. (29a) for C3 deposition onto Mycobacteria. Briefly, Serratia \#21 was grown on $\mathrm{M}-\mathrm{H}$ plates overnight and resuspended to an $\mathrm{A}_{640}$ of 0.6 in PBS. 1-ml aliquots of this suspension were placed in microfuge tubes, pelleted, and washed with PBS. The bacteria were then suspended in $200 \mu \mathrm{l}$ of anti-Gal $(100 \mu \mathrm{g} / \mathrm{ml})$ in PBS or in $200 \mu \mathrm{l}$ of PBS without anti-Gal for $30 \mathrm{~min}$ at room temperature. The bacteria were then pelleted and washed three times with PBS. Hypo $\gamma$ serum or heatinactivated hypor serum was added to the bacterial pellet to effect a $40 \%$ final serum concentration in PBS in a total vol of $400 \mu$ l and the mixture was incubated for $1 \mathrm{~h}$ at $37^{\circ} \mathrm{C}$. The bacteria were then collected by centrifugation, washed with PBS, and then resuspended in 1 $\mathrm{ml}$ of PBS. Triplicate $100-\mu$ l aliquots of this suspension $\left(10^{8}\right.$ bacteria) were dispensed into the wells of a microtiter plate and were allowed to sensitize these wells for $1 \mathrm{~h}$. Each well was then washed, incubated with $0.1 \%$ BSA for $30 \mathrm{~min}$ to block nonspecific protein binding sites, washed again with PBS, and then incubated for $2 \mathrm{~h}$ at $\mathrm{RT}$ with a 1:100 solution in $0.1 \%$ BSA of alkaline phosphatase-linked goat anti-human C9 (E-Y Laboratories Inc.). The wells were then washed extensively and a $p$-nitrophenyl phosphate disodium substrate was added $(2 \mathrm{mg} / \mathrm{ml}$ in 100 $\mathrm{mM}$ sodium bicarbonate, $10 \mathrm{mM} \mathrm{MgCl}$, $\mathrm{pH} 9.5$ ) (Sigma Chemical Co.). The absorbance of the solution in the plates was read with a 405-nm filter on an ELISA reader (2550; Bio-Rad) after $2 \mathrm{~h}$ of incubation with the substrate. The mean and standard deviation of the absorbance for triplicate wells of each type was calculated. Controls including bacteria that were not incubated in serum, bacteria incubated with heat-inactivated serum (see above), and wells containing no bacteria were included. 
Table I. Comparison of Anti-Gal Binding to Blood and Normal Stool Isolates*

\begin{tabular}{|c|c|c|c|c|c|}
\hline $\begin{array}{c}\text { Site of } \\
\text { isolation }\end{array}$ & Organism & $n$ & $\begin{array}{l}\text { Number positive } \\
\text { for anti-Gal }\end{array}$ & Percent & $P$-value \\
\hline \multirow[t]{7}{*}{ Blood } & Escherichia coli & 36 & 36 & 100 & \\
\hline & Klebsiella-Enterobacter-Serratia & 41 & 17 & 41 & \\
\hline & Citrobacter & 2 & 2 & 100 & \\
\hline & Proteus & 3 & 3 & 100 & \\
\hline & Pseudomonadaceae & 9 & 4 & 44 & \\
\hline & Others & 4 & 1 & 25 & \\
\hline & Total & 95 & 63 & 66 & \\
\hline \multirow[t]{7}{*}{ Normal stool } & Escherichia coli & 15 & 6 & 40 & 0.0002 \\
\hline & Klebsiella-Enterobacter-Serratia & 9 & 0 & 0 & 0.02 \\
\hline & Citrobacter & 2 & 0 & 0 & NA \\
\hline & Proteus & 0 & 0 & 0 & NA \\
\hline & Pseudomonadaceae & 0 & 0 & 0 & NA \\
\hline & Others & 1 & 1 & 100 & NA \\
\hline & Total & 27 & 7 & 26 & 0.0002 \\
\hline
\end{tabular}

* Binding of anti-Gal to these Gram-negative bacteria was done using a dot blot assay. Agar-grown organisms were dotted onto nitrocellulose, incubated first in $1 \%$ casein, then in a $2 \mu \mathrm{g} / \mathrm{ml}$ solution of anti-Gal for $2 \mathrm{~h}$ and lastly with an alkaline phosphatase-conjugated goat anti-human IgG. The blots were then developed with a substrate solution containing naphtol and Fast Red TR salt. This experiment was repeated at least three times for each organism. NA, not applicable.

Effect of anti-Gal on membrane attack complex (MAC) formation on Serratia \#21. Detection of the MAC on Serratia \#21 was done by immunoelectronmicroscopy (30) using a monoclonal anti-human C5b-9 antibody (Quidel, San Diego, CA) that recognizes a neoantigen on assembled MAC and does not bind to nascent C9.

Briefly, S. marcescens \#21 was grown on M-H agar, pelleted, fixed with $2 \%$ paraformaldehyde and $0.1 \%$ glutaraldehyde, dehydrated with 2.3 M sucrose and then sectioned onto copper grids. The sectioned organisms were either presensitized or not with anti-Gal $(100 \mu \mathrm{g} / \mathrm{ml})$ for $30 \mathrm{~min}$ and then incubated for $1 \mathrm{~h}$ with $20 \%$ hypo $\gamma$ serum or with heat-inactivated hypor serum. After several washes with PBS, the organism was reacted with monoclonal anti-human C5b-9 IgG (1:100 in PBS) for $1 \mathrm{~h}$ at RT and then goat anti-mouse IgG conjugated to gold $(15 \mathrm{~nm})(1: 500$ in PBS) for $30 \mathrm{~min}$ at RT.

\section{Results}

Prevalence of binding of anti-Gal to Gram-negative human isolates. The prevalence of bacteria that bound anti-Gal was significantly $\left(P=2 \times 10^{-4}\right)$ higher among isolates from the blood of patients with Gram-negative sepsis $(66 \%)$ than among those from the stools of healthy laboratory volunteers (26\%) (Table I). All Escherichia coli blood isolates bound anti-Gal, compared to only $40 \%$ of normal stool isolates $\left(P=2 \times 10^{-4}\right)$. Blood isolates of Klebsiella-Enterobacter-Serratia also bound anti-Gal significantly more often than stool isolates of the same species $(P=0.02)$. There were not enough of the other species for meaningful comparisons.

The higher prevalence of binding of anti-Gal to blood isolates as compared to stool isolates and its binding to all of the $E$. coli blood isolates raised the possibility that the antibody could enhance the ability to survive within the bloodstream of bacteria that bound it. We began our investigation of this possibility by studying the effects of anti-Gal on complement-mediated killing of two representative Serratia marcescens strains that caused sepsis.
Effect of anti-Gal on the complement-mediated lysis of Serratia \#21 and \#7. As can be seen in Fig. 1, S. marcescens \#21 was resistant to complement-mediated killing by NHS (Ser'); however, a hypogammaglobulinemic serum that had

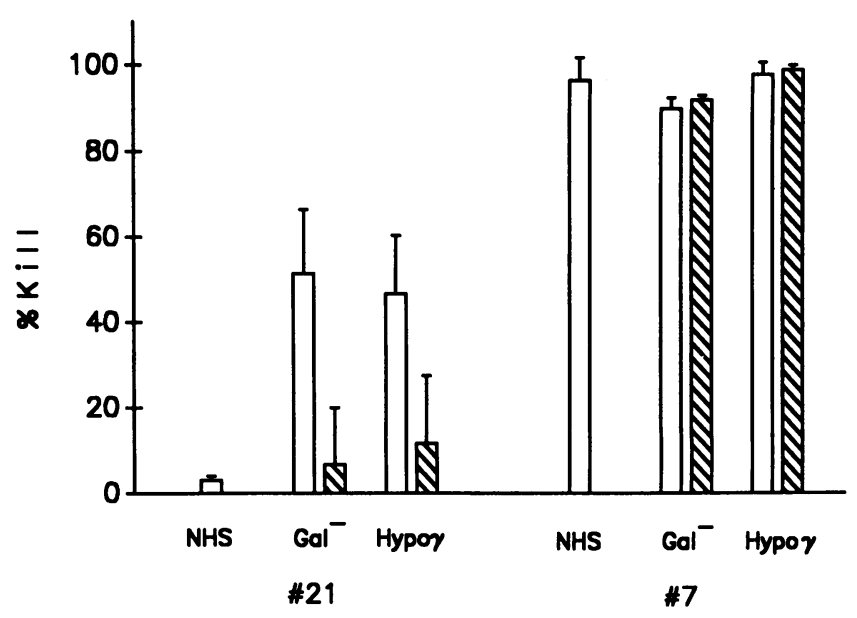

Figure 1. Serum bactericidal activity against Serratia \#21 and \#7. Sera tested are indicated on the figure. Hatched bars represent sera to which anti-Gal was added. Reaction mixtures were prepared by combining equal volumes of the diluted bacterial suspension and a test serum ( $20 \%$ final concentration). We tested the following sera (from left to right for each organism): normal human sera (NHS), NHS depleted of anti-Gal (Gal-NHS), hypogammaglobulenemic sera that contained less than $10 \%$ normal anti-Gal levels (Hypor). Anti-Gal was added to these sera in a concentration equal to that it has in NHS $(100 \mu \mathrm{g} / \mathrm{ml})$ (hatched bars). The reaction mixtures were incubated at $37^{\circ} \mathrm{C}$ for $1 \mathrm{~h}$. Bactericidal activity was determined by comparing the number of survivors in reaction mixtures containing active serum to those in mixtures containing heat-inactivated sera. The results in this figure represent the analysis of more than 10 bactericidal assays. 
$<5 \%$ of the normal NHS level of anti-Gal, and no detectable antibodies that bound Serratia \#21, could kill it. NHS from which anti-Gal had been completely removed ( $\mathrm{Gal}^{-}$serum) also killed Serratia \#21, and to the same extent as the hypor serum (Fig. 1). When anti-Gal was added to $\mathrm{Gal}^{-}$or hypor serum to a concentration equal to that in NHS $(100 \mu \mathrm{g} / \mathrm{ml})$, these sera were no longer able to kill Serratia \#21 (Fig. 1) ( $P$ $=0.004$ for $\mathrm{Gal}^{-}$sera \pm anti-Gal; $P=0.001$ for hypo $\gamma$ sera \pm anti-Gal). Anti-Gal blockade of lysis of Serratia \#21 therefore appeared to account for the organism's NHS resistance.

Anti-Gal binds to terminal $\alpha$ galactosyl residues. The blocking effect of anti-Gal on NHS killing of Serratia \#21 was partially reversed by $\alpha$ methyl galactoside but not by lactose (galactose $\beta 1,4$ glucose) or sucrose (glucose $\alpha 1,2$ fructose) (Fig. 2 ), suggesting that its effect does indeed depend on binding to $\alpha$ galactosyl residues.

S. marcescens \#7 was serum sensitive ( $\mathrm{Ser}^{5}$ ) (Fig. 1); both hypo $\gamma$ and $\mathrm{Gal}^{-}$sera killed this strain as well as did whole NHS, confirming that anti-Gal did not affect its killing by NHS (Fig. 1).

Pathway of complement activation by Serratia \#21 and \#7. Fig. 3 shows that killing of strain \#21 by hypo $\gamma$ and $\mathrm{Gal}^{-}$sera was effected through ACP. Chelation of these sera with MgEGTA to abolish the classical pathway (CP) did not diminish their lysis of Serratia \#21 organisms. When anti-Gal was added to the chelated sera, they no longer killed Serratia \#21 (Fig. 3). Strain \#21 could not be killed by $\mathrm{P}^{-}$serum (results not shown), confirming that these organisms could not be lysed through the CP.

In contrast, strain \#7 was killed equally well through the $C P$ and the ACP (Fig. 4). Killing of strain \#7 through the ACP required properdin. The $\mathrm{CP}$ killing of \#7 was abolished when specific antibody was absorbed from $\mathrm{P}^{-}$serum or the $\mathrm{CP}$ in $\mathrm{P}^{-}$ serum was abolished by MgEGTA chelation (Fig. 4).

The exquisite sensitivity of strain \#7 to lysis by $20 \%$ NHS

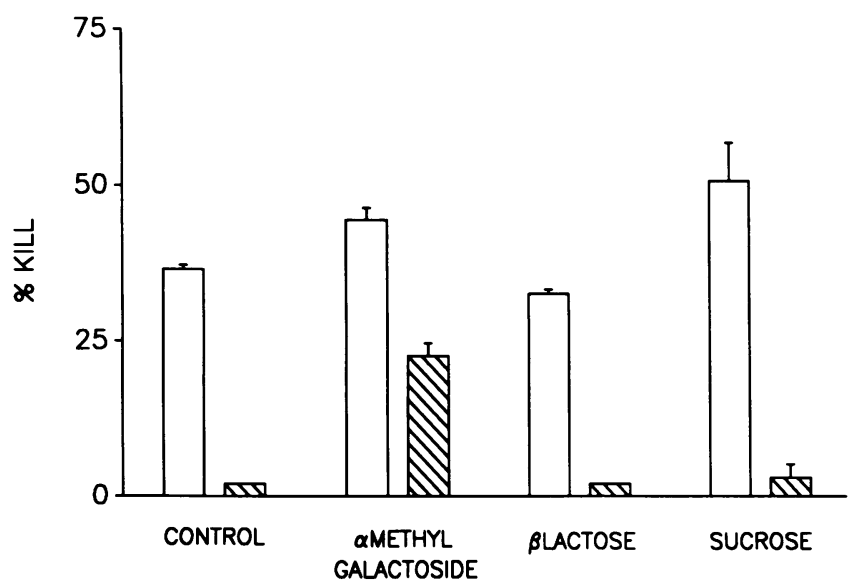

Figure 2. Specificity of the anti-Gal antibactericidal effect on Serratia \#21. We followed the same method detailed in Fig. 1 except that reaction mixtures also contained a test carbohydrate inhibitor ( $\alpha$ methyl galactoside, $\beta$ lactose, or sucrose) at a $100 \mathrm{mM}$ final concentration. Open bars represent Hypor sera without added anti-Gal. Hatched bars represent Hypo $\gamma$ sera with anti-Gal. Note that only $\alpha$ methyl galactoside (but not $\beta$ lactose or sucrose) was able to partially inhibit the blocking effect of anti-Gal on ACP-mediated killing of Serratia \#21 by Hypo $\gamma$ sera.

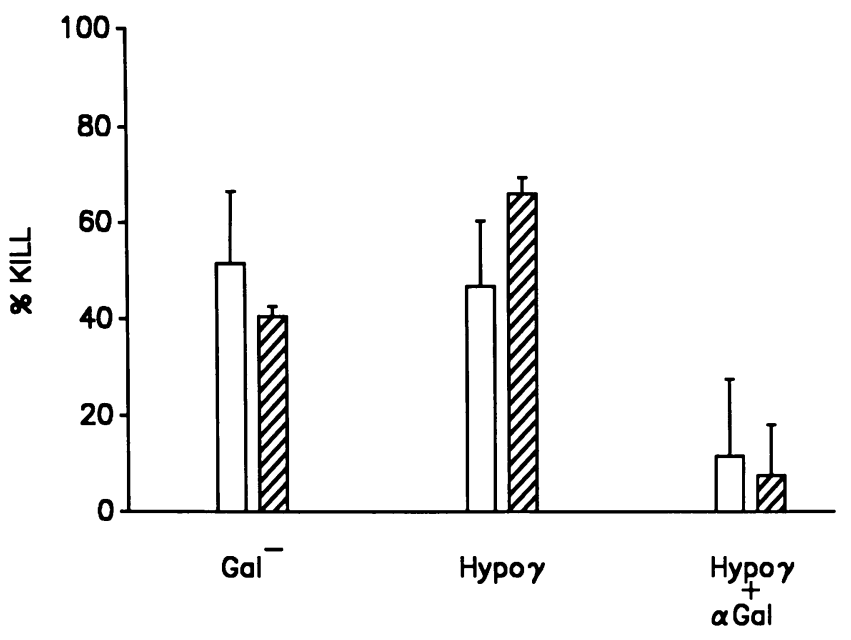

Figure 3. Serum bactericidal activity against Serratia \#21. We followed the same method detailed in Fig. 1 and tested Hypo $\gamma$ and $\mathrm{Gal}^{-}$ sera. Hatched bars here represent sera chelated with $10 \mathrm{mM} \mathrm{Mg}$ EGTA and therefore unable to activate the classical complement pathway. Note that Serratia \#21 is partially killed by the ACP of both Hypo $\gamma$ and $\mathrm{Gal}^{-}$sera and that the anti-Gal-mediated blockade of that killing is mediated through the ACP and is significant $(P=0.018$ for chelated Hypor with/without anti-Gal).

made it difficult to assess whether anti-Gal was augmenting its killing. Under complement limiting conditions (10\% final serum concentration), however, the addition of anti-Gal to MgEGTA-chelated hypo $\gamma$ serum resulted in a modest but significant increase in ACP killing $(P=0.03$ for chelated $10 \%$ hypo $\gamma$ sera \pm anti-Gal) (Fig. 5).

Binding of anti-Gal to $S$. marcescens \#21 and \#7. The opposite effects of anti-Gal on the ACP-mediated lysis of the two Serratia led us to investigate whether there were differences in the number of binding sites for anti-Gal on the two strains. Serratia \#7 did bind significantly more anti-Gal molecules

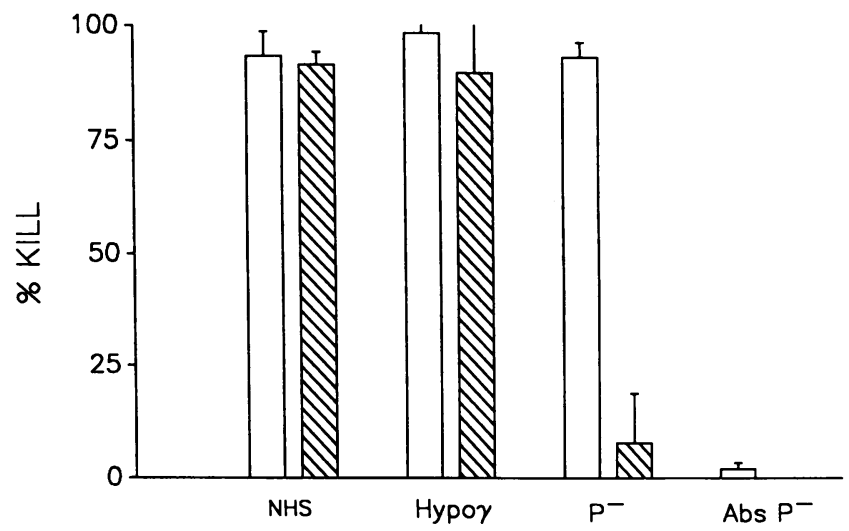

Figure 4. Serum bactericidal activity against Serratia \#7. We followed the same method detailed in Fig. 1. We tested the following sera: NHS, Hypor sera, properdin deficient $\left(\mathrm{P}^{-}\right)$sera and $\mathrm{P}^{-}$absorbed with strain \#7 (Abs $\left.\mathrm{P}^{-}\right)$. Hatched bars represent sera chelated with $\mathrm{Mg}$ EGTA. Note that strain \#7 is serum sensitive and killed by both the $\mathrm{ACP}$ and the $\mathrm{CP}$. The ACP kill is highly dependent on properdin (minimal kill in $\mathrm{P}^{-}$MgEGTA-chelated sera). The CP kill is dependent on specific antibody (minimal kill in absorbed $\mathrm{P}^{-}$sera). 


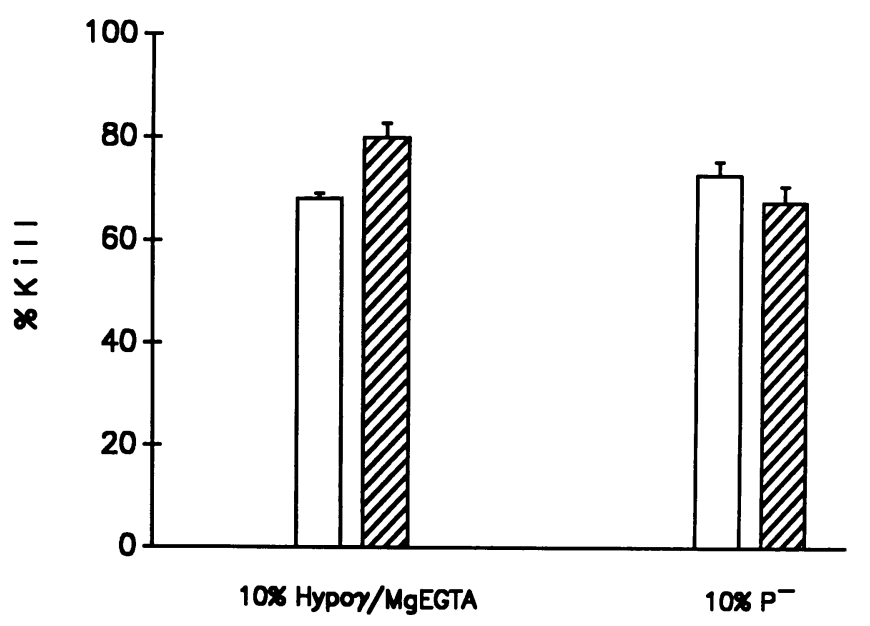

Figure 5. Effect of anti-Gal on the complement-mediated killing of Serratia \#7. We followed the same method detailed in Fig. 1 except that the final concentration of the Hypor sera used in this experiment was only $10 \%$. Open bars represent Hypo $\gamma$ sera without added antiGal. Hatched bars represent Hypo $\gamma$ sera with added anti-Gal. Note that anti-Gal enhances the ACP killing of Serratia $\# 7(P=0.03$ for chelated Hypor serum with/without anti-Gal).

than did Serratia \#21 (Fig. 6). The binding of ${ }^{125} \mathrm{I}$-anti-Gal to both strains could be completely displaced by a 50 -fold excess of cold anti-Gal (Table II).

An alternative explanation for the opposite effects of antiGal could be that it bound to different structures on the surfaces of the two strains. Figs. 7 and 8 show that anti-Gal bound to $S$. marcescens \#21 LPS (regularly spaced middle and high $M_{\mathrm{r}}$

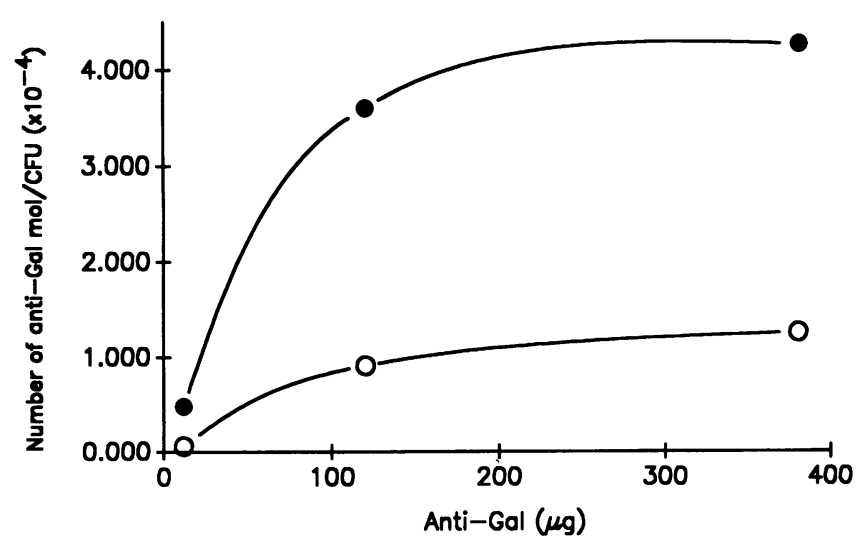

Figure 6. Binding of anti-Gal to Serratia \#21 and \#7 whole organisms. Affinity-purified anti-Gal was radiolabeled to a sp act of $1.85 \times 10^{5}$ $\mathrm{cpm} / \mu \mathrm{g}$ by the lactoperoxidase iodination procedure. Serratia $\# 21$ and \#7 were grown for $24 \mathrm{~h}$ on $\mathrm{MH}$ agar, suspended to an $\mathrm{A}_{640}$ of 0.6 in PBS. Aliquots of $100 \mu \mathrm{l}$ of this suspension were put in microfuge tubes, and the bacteria collected and washed with PBS by centrifugation. ${ }^{125} \mathrm{I}$-anti-Gal $(12,120$, or $390 \mu \mathrm{g})$ was then added and the mixture incubated for $60 \mathrm{~min}$ at $37^{\circ} \mathrm{C}$. The organisms were washed by repeated centrifugation in PBS and radiolabeled bound anti-Gal was counted in a gamma counter. We determined the number of CFU $/ \mathrm{ml}$ for each organism and calculated the number of molecules of ${ }^{125} \mathrm{I}$ anti-Gal bound per CFU. As shown in this figure, anti-Gal binds to both Serratia \#21 and \#7 but significantly more to Serratia \#7 ( $P$ $<0.01$ for $390 \mu \mathrm{g}$ anti-Gal binding points).
Table II. Cold anti-Gal Displacing ${ }^{125}$ I-anti-Gal Binding to Serratia \#21 and \#7

\begin{tabular}{lr}
\multicolumn{1}{c}{ Reaction mixture* } & \multicolumn{1}{c}{ cpm } \\
\hline control (no bacteria) & 2,257 \\
$\# 21+12 \mu \mathrm{g}^{125}-\mathrm{I} \alpha \mathrm{Gal}$ & 12,997 \\
$\# 21+12 \mu \mathrm{g}{ }^{125} \mathrm{I}-\alpha \mathrm{Gal}+600 \mu \mathrm{g}$ cold $\alpha \mathrm{Gal}$ & 2,305 \\
$\# 7+12 \mu \mathrm{g}{ }^{125} \mathrm{I}-\alpha \mathrm{Gal}$ & 64,915 \\
$\# 7+12 \mu \mathrm{g}{ }^{125} \mathrm{I}-\alpha \mathrm{Gal}+600 \mu \mathrm{g}$ cold $\alpha \mathrm{Gal}$ & 1,009 \\
\hline
\end{tabular}

* We followed the method detailed in Fig. 6 except that $12 \mu \mathrm{g}$ of anti-Gal was added to the organisms. We then added a 50-fold excess of cold anti-Gal to duplicate reaction mixtures and counted these similarly using a gamma counter.

bands), but not to $S$. marcescens \#7 LPS or outer membrane proteins. We obtained identical binding patterns to the two Serratia when the samples were treated with proteinase K (not shown), indicating that anti-Gal did not bind to outer membrane proteins. Anti-Gal binding of Serratia \#21 LPS varied in intensity as the number of repeating LPS units changed; no binding to low $M_{\mathrm{r}}$ LPS components or to core LPS was detected (Fig. 7). The pattern of binding of anti-Gal to Serratia \#21 was not a function of when the strain was sampled in its growth cycle; the lack of binding of anti-Gal to Serratia \#7 was also not a function of growth time (Fig. 8, $A$ and $B$ ). In addi-

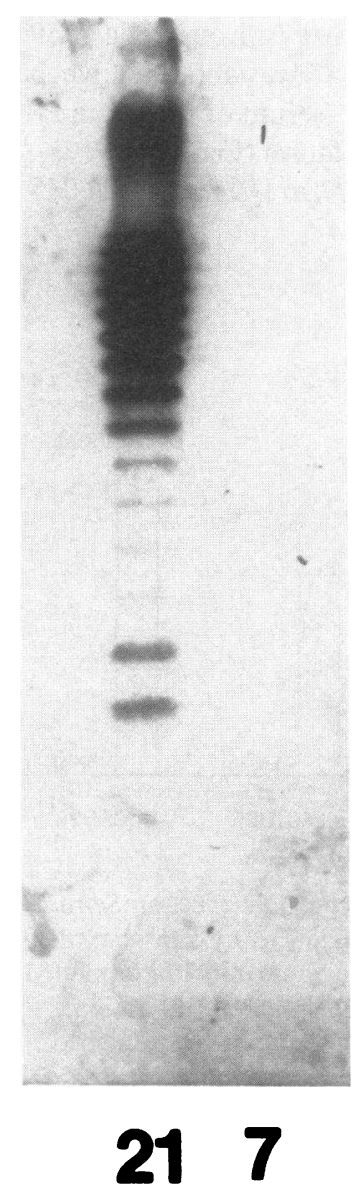

Figure 7. Immunoblot with anti-Gal of SDS-PAGE-separated LPS of Serratia \#21 and \#7. Samples were dissolved in $2 \%$ SDS, applied to discontinuous slab gels (3\% acrylamide spacer gel, $13 \%$ resolving gel), electrophoresed at $10 \mathrm{~mA}$ current for 4-5 $h$ and transferred to nitrocellulose overnight. The transblot was reacted with anti-Gal $(100 \mu \mathrm{g} / \mathrm{ml})$, and then incubated with an alkaline phosphatase-conjugated goat anti-human IgG. Note that Serratia \#21 LPS bound anti-Gal but Serratia \#7 LPS did not. 
A

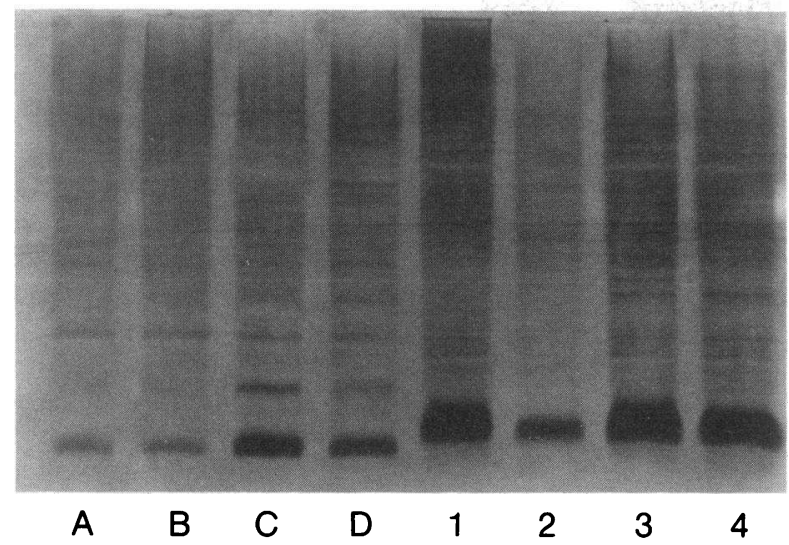

B

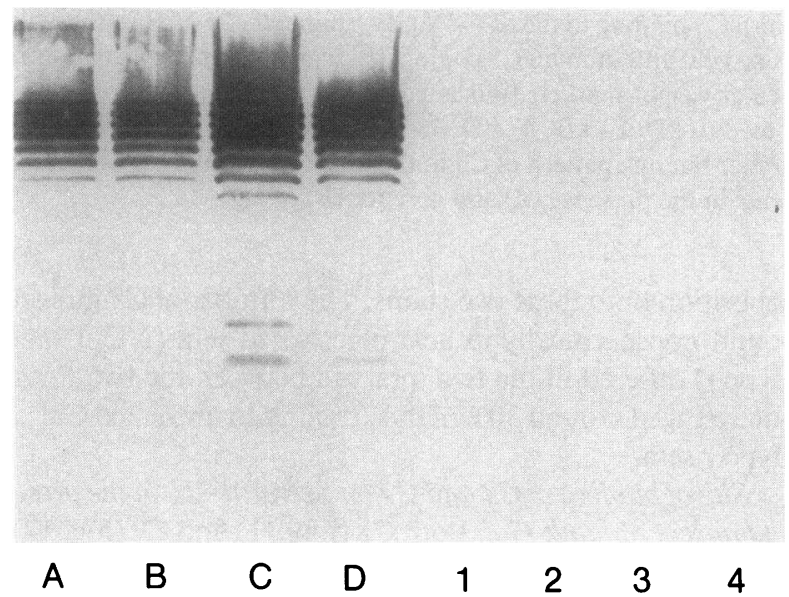

Figure 8. Silver stain $(A)$ and immunoblot with anti-Gal $(B)$ of SDSPAGE-separated lysates of Serratia \#21 and \#7 sampled at different times in their growth cycle. Growth times examined (from left to right) are: $3 \mathrm{~h}, 6 \mathrm{~h}, 12 \mathrm{~h}$, and $24 \mathrm{~h}$. Lanes $A, B, C$, and $D$ represent Serratia \#21. Lanes 1, 2, 3, and 4 represent Serratia \#7. We followed the method detailed in Fig. 7. Note that Serratia $\# 21$ bound anti-Gal at all time points but that Serratia \#7 did not.

tion, the binding of anti-Gal to \#21 LPS appeared to be specific as evidenced by unaltered binding of biotinylated anti-Gal to \#21 LPS by Western blot when $\mathrm{Gal}^{-}$serum was used instead of $1 \%$ casein to block nonspecific binding sites (results not shown).

The lipopolysaccharides of Serratia \#21 and \#7 differed in their ability to bind anti-Gal and other antibodies in NHS. Anti-Gal was the only antibody in NHS that bound \#21 LPS, as $\mathrm{Gal}^{-}$serum did not bind to \#21 LPS by Western blot (results not shown). In contrast, Serratia \#7 LPS did not bind anti-Gal. However, there was strong binding of both NHS and $\mathrm{Gal}^{-}$ serum to \#7 LPS indicating the presence of specific LPS antibodies in NHS that are not anti-Gal (results not shown).

Although the LPS of Serratia \#7 did not bind anti-Gal (Figs. 7, 8, and Fig. 9), its purified capsular polysaccharide did (Fig. 10). In contrast, the capsular polysaccharide of Serratia \#21 did not bind anti-Gal (Fig. 10), but its LPS did (Figs. 7, 8, and 9). This means that the digalactose structure to which antiGal binds is present in different organelles (LPS or capsular polysaccharide) on these two Serratia. The results obtained using $\mathrm{Gal}^{-}$to block nonspecific binding sites were identical to

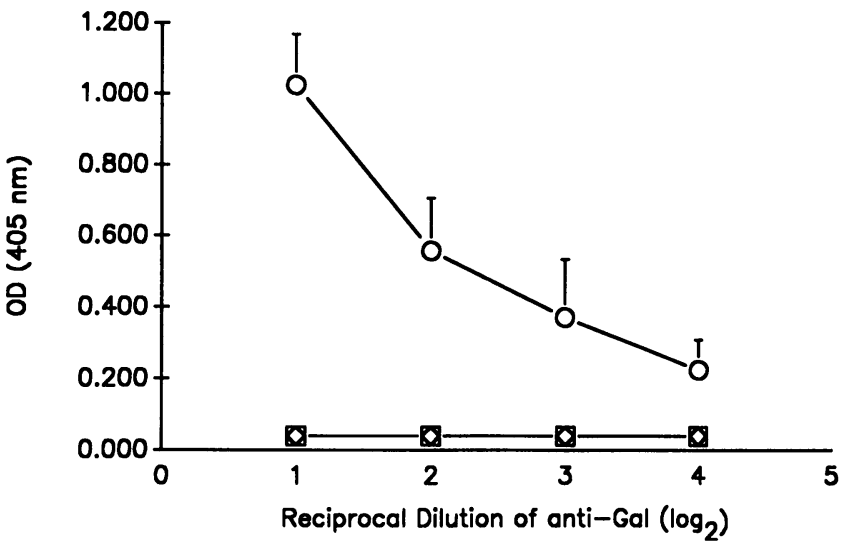

Figure 9. Anti-Gal binding to \#21 LPS $(0-0)$ and \#7 LPS ( $\square-\square)$ by ELISA. Binding of \#21 LPS to anti-Gal absorbed with Serratia \#7 whole organism $(\diamond-\diamond)$ by ELISA. We followed the same method outlined in Fig. 9 except that the wells of the microtiter plates were not precoated with poly-L-lysine. Note that only Serratia \#21 LPS binds to anti-Gal. Anti-Gal loses its ability to bind to \#21 LPS when it is preabsorbed with Serratia \#7. This again suggests that the specificity of anti-Gal on these two organisms is similar.

those we got using $0.1 \%$ BSA as the blocking agent (not shown). This shows that anti-Gal was bound specifically to \#7 capsular polysaccharide and \#21 LPS.

Anti-Gal is a polyclonal antibody, and different clonal populations could be binding to the two Serratia and producing opposite ACP effects. Absorptions of anti-Gal with Serratia \#21 or \#7 not only abolished binding to the absorbing organisms' LPS or K antigen, respectively, but also abolished bind-

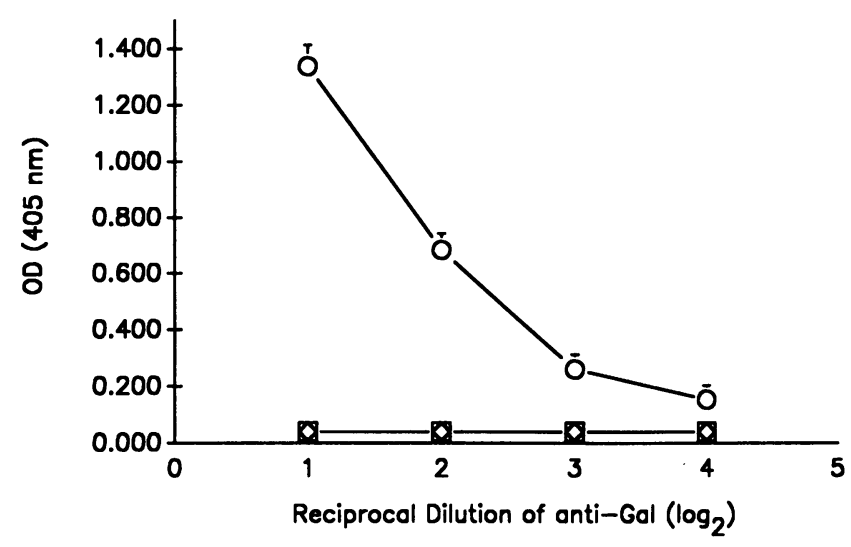

Figure 10. Anti-Gal binding to Serratia \#7 ( -0$)$ and \#21 (口- $\square$ ) capsular polysaccharides by ELISA. Binding of Serratia \#7 capsular polysaccharide $(\diamond-\diamond)$ to anti-Gal absorbed with Serratia \#21 whole bacteria by ELISA. The capsular polysaccharides $(50 \mu \mathrm{g} / \mathrm{ml})$ sensitized the wells of a microtiter plate that were previously coated with poly-L-lysine $\left(47,000 M_{\mathrm{r}}\right)$. Wells were incubated for $1 \mathrm{~h}$ with serial twofold dilutions of a $100-\mu \mathrm{g} / \mathrm{ml}$ anti-Gal or absorbed anti-Gal solutions and then reacted with goat anti-human IgG conjugated to alkaline phosphatase. Note that only Serratia \#7 capsular polysaccharide (and not Serratia \#21 capsule) bound anti-Gal. Also note that antiGal absorbed with Serratia \#21 whole bacteria looses its ability to bind Serratia \#7 capsule, suggesting a shared anti-Gal specificity on these two organisms. 
ing to the other organisms' outer membrane antigen (Figs. 9 and 10). Thus the same antibody within the anti-Gal polyclonal pool appeared to be binding to both Serratia, but to different outer membrane antigens.

Effect of anti-Gal on deposition of $C 3$ and $C 9$ onto Serratia \#21 LPS. Binding of anti-Gal to Serratia \#21 might block ACP activation by several mechanisms. It might occupy the LPS $\mathrm{C} 3 \mathrm{~b}$ binding site or sterically hinder the binding of $\mathrm{C} 3 \mathrm{~b}$ to neighboring LPS sites. In either event, the number of molecules of C3 bound to Serratia \#21 would decrease. Anti-Gal also might accelerate the decay of bound $\mathrm{C} 3 \mathrm{~b}$ or decrease the affinity of $\mathrm{C} 3 \mathrm{~b}$ for factor $\mathrm{B}$, thereby interfering with effective assemblage of the ACP C3 convertase. Alternatively, it might redirect bound $\mathrm{C} 3 \mathrm{~b}$ to sites further away from the bacterial outer membrane, thereby making it more difficult for the MAC to find sites into which it could embed, or change the molecular configuration of the MAC.

Effect of anti-Gal on the number of $C 3$ molecules deposited onto Serratia \#21 and \#7. We used two different ${ }^{125} \mathrm{I}-\mathrm{C} 3$ preparations to quantitate $\mathrm{C} 3$ deposition onto both Serratia by $\mathrm{Gal}^{-}$ and Hypor sera, respectively. Both $\mathrm{C} 3$ preparations were radiolabeled using iodobeads from Pierce, and both had a poorly radiolabeled $\beta$ chain (not shown). However, these two preparations lost only $10-30 \%$ of normal C3 hemolytic activity (28).

The number of molecules of $\mathrm{C} 3$ deposited specifically onto Serratia \#21 by hypo $\gamma$ or $\mathrm{Gal}^{-}$MgEGTA-chelated sera was similar in the absence and presence of anti-Gal (Table III). Anti-Gal also had very little effect on the number of molecules of $\mathrm{C} 3$ deposited by either serum onto Serratia \#7, even though Serratia \#7 bound significantly more molecules of anti-Gal than Serratia \#21. Note that the number of molecules of $\mathrm{C3}$ deposited onto strain \#7 and onto strain \#21 by hypor MgEGTA-chelated serum was less than that deposited by $\mathrm{Gal}^{-}$ MgEGTA-chelated serum suggesting that antibodies other than anti-Gal in the latter serum were contributing to ACP C3

Table III. C3 Deposition on Serratia \#21 and \#7

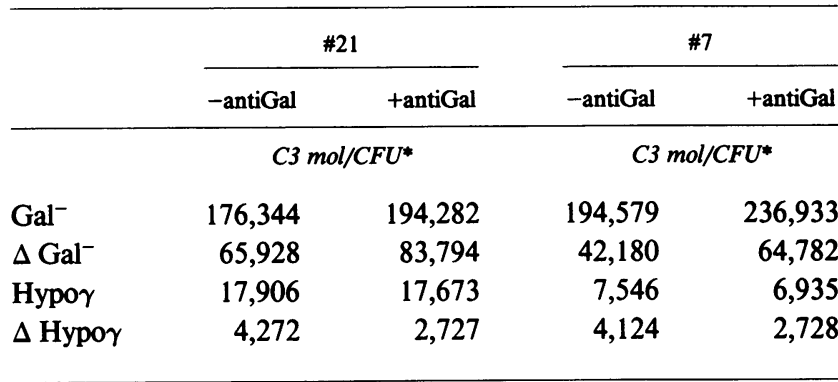

* Serratia \#21 and \#7 (10 $\left.10^{8}-10^{9} \mathrm{CFU}\right)$ were either presensitized or not with $20 \mu \mathrm{g}$ of anti-Gal for $30 \mathrm{~min}$ at room temperature. We then added to the bacteria either $20 \% \mathrm{MgEGTA}$-chelated serum (Gal ${ }^{-}$or Hypo $\gamma$ ) or heat-inactivated $(\Delta)$ MgEGTA-chelated serum that contained ${ }^{125}$ I-labeled C3 at a ratio of labeled to unlabeled C3 of 1:44 and incubated them for $1 \mathrm{~h}$ at $37^{\circ} \mathrm{C}$. The specific activity of the $\mathrm{C} 3$ was $1.22 \times 10^{5}$ for experiments with $\mathrm{Gal}^{-}$serum and $1.5 \times 10^{6}$ for those with Hypo $\gamma$ serum. After pelleting the bacteria, we washed them in PBS/0.1\% SDS and resuspended them in PBS. We counted aliquots that contained $10^{8} \mathrm{CFU}$ in a gamma scintillation counter and determined the number of bound $\mathrm{C} 3$ molecules per CFU by multiplying the number of ${ }^{125} \mathrm{I}-\mathrm{C} 3$ molecules deposited by the dilution factor of 45.

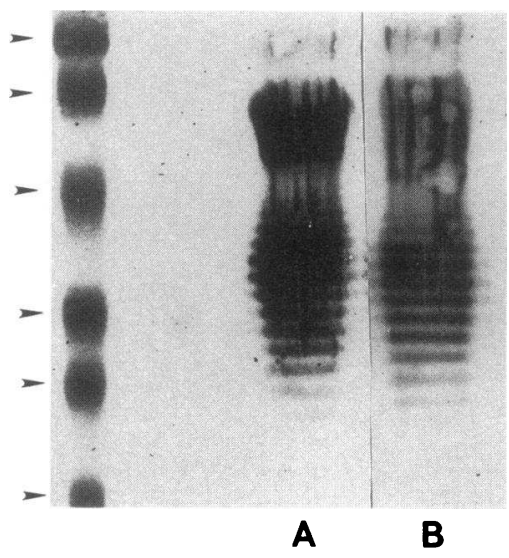

Figure 11. Immunoblot of Serratia \#21 LPS with anti-C3. The \#21 LPS was separated by SDS-PAGE and transferred to nitrocellulose as detailed in Fig. 7 and then reacted with $10 \%$ Hypor sera with and without anti-Gal. The Hypor serum used had no anti-LPS antibodies against strain \#21 and had very low levels of anti-Gal antibody ( $<5 \%$ NHS concentra-

tion). C3 binding to the SDS-PAGE-separated \#21 LPS was visualized using goat anti-human $\mathrm{C} 3$ conjugated to alkaline phosphatase. Molecular weight markers (indicated by the arrows) are from top to bottom: $110 \mathrm{kD}, 84 \mathrm{kD}, 47 \mathrm{kD}, 33 \mathrm{kD}, 24 \mathrm{kD}$, and $16 \mathrm{kD}$. Note the similar binding pattern of $\mathrm{C} 3$ to the high and middle $M_{\mathrm{r}}$ LPS components in the presence $(A)$ and absence $(B)$ of anti-Gal.

deposition onto these two stains. The number of $\mathrm{C} 3$ molecules bound nonspecifically in heat-inactivated sera ( $\Delta \mathrm{Gal}^{-}$and $\Delta$ Hypor) differed in the two sera and between the two Serratia but averaged around $30 \%$ of those bound to untreated $\mathrm{Gal}^{-}$and Hypor sera.

Site of binding of $C 3$ and $C 9$ on Serratia \#21 in the presence and absence of anti-Gal. Both C3 (Fig. 11) and C9 (Fig. 12), as detected by their antibodies, bound to the same LPS molecules as did anti-Gal, and their binding was not changed or inhibited by the presence of anti-Gal. There was no C3 nor C9 binding when heat-inactivated serum was used (Fig. 13 for C3; results not shown for C9).
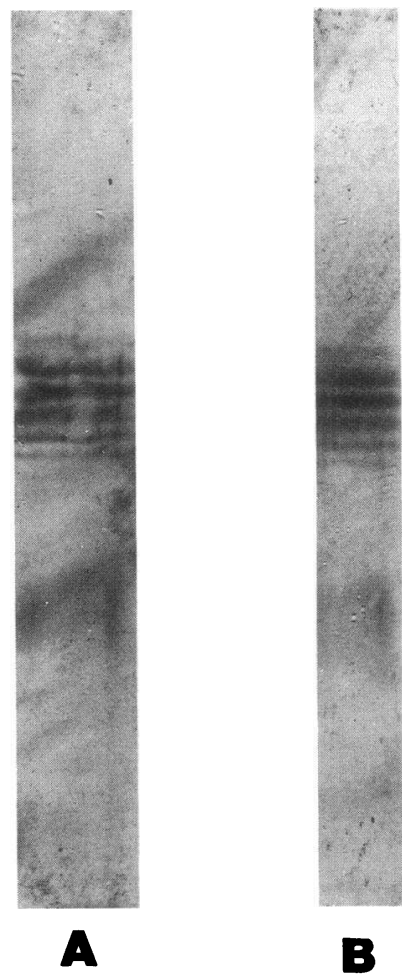

Figure 12. Immunoblot of Serratia \#21 LPS with anti-C9. We followed the method detailed in Fig. 11 except that we visualized C9 binding to the SDSPAGE-separated LPS with goat anti-human $\mathrm{C} 9$ conjugated to alkaline phosphatase. Note the similar binding pattern of $\mathrm{C} 9$ to the \#21 LPS in the presence $(A)$ and absence $(B)$ of anti-Gal. 
Preincubation of Serratia \#21 LPS with hypo $\gamma$ serum (allowing for $\mathrm{C} 3$ to bind first), followed by incubation with antiGal, did not abolish the binding of anti-Gal to its cognitive epitope on \#21 LPS (Fig. 13). This indicates that anti-Gal and C3 have distinct binding sites on \#21 LPS. Anti-Gal therefore does not compete for the same receptor as C3 on \#21 LPS and also does not seem to interfere with the deposition of $\mathrm{C} 9$ onto this antigen.

Effect of anti-Gal on the molecular form of bound C3 fragments on Serratia \#21 and \#7. SDS-PAGE analysis of the C3 fragments released from strain \#21 and strain \#7 after incubation with hypo $\gamma$ MgEGTA-chelated sera showed that C3b $(\alpha$ chain $M_{\mathrm{r}} 105,000, \beta$ chain $\left.M_{\mathrm{r}} 75,000\right)$, iC $3 \mathrm{~b}\left(\alpha^{\prime}\right.$ chain $M_{\mathrm{r}}$ 67,000 and 40,000 , and $\beta$ chain $M_{\mathrm{r}} 75,000$ ) and a lower molecular weight fragment $\left(M_{\mathrm{r}} 16,000\right)$ were released from Serratia \#21 and from Serratia \#7 (Fig. 14). The major fragment released from strain \#21 was $\mathrm{iC} 3 \mathrm{~b}$. The $16-\mathrm{kD}$ fragment was also clearly visible. The $\alpha$ chain of C3b was minor.

Anti-Gal had no effect on the fragmentation pattern of $\mathrm{C} 3$ onto these two bacteria; identical patterns were observed in the presence and absence of anti-Gal. Also note also that Serratia \#21 and \#7 had very similar C3 fragmentation patterns when incubated in hypo $\gamma$ serum containing anti-Gal, despite the opposite effects that this antibody had on the complement-mediated lysis of these bacteria.

To further evaluate the nature of the $16-\mathrm{kD} \mathrm{C} 3$ degradation product, identical transblots were incubated with goat anti-human C3d. This latter antibody bound the $16-\mathrm{kD}$ band, indicating that this product may be a lower molecular weight fragment of C3d (results not shown).

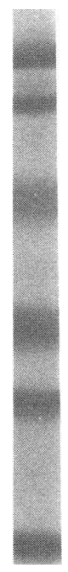

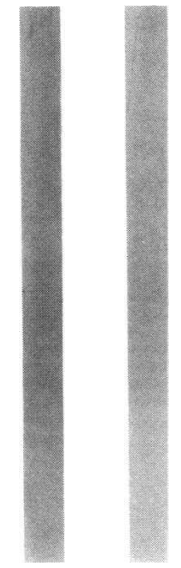

A B

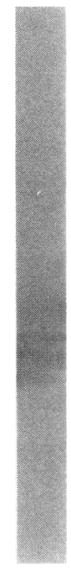

B C

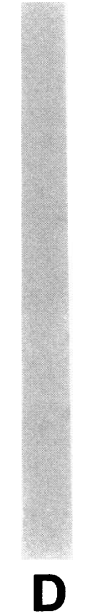
then incubated with goat anti-human IgG and developed. Note th anti-Gal binds to Serratia \#21 LPS under these experimental conditions and in a pattern similar to that shown in lane $A$. Lane $C$ represents the same experiment as in Panel $A$ except that goat anti-human C3 was used as secondary antibody. Note that C3 binds to Serratia \#21 LPS under these experimental conditions. Lane $D$ represents Serratia \#21 LPS incubated with 10\% heat-inactivated Hypor serum, then with anti-Gal, and finally with goat anti-human C3. Note that C3 does not bind to \#21 LPS when heat-inactivated serum is used. Molecular weight markers are from top to bottom: $110 \mathrm{kD}, 84 \mathrm{kD}$, $47 \mathrm{kD}, 33 \mathrm{kD}, 24 \mathrm{kD}$, and $16 \mathrm{kD}$.

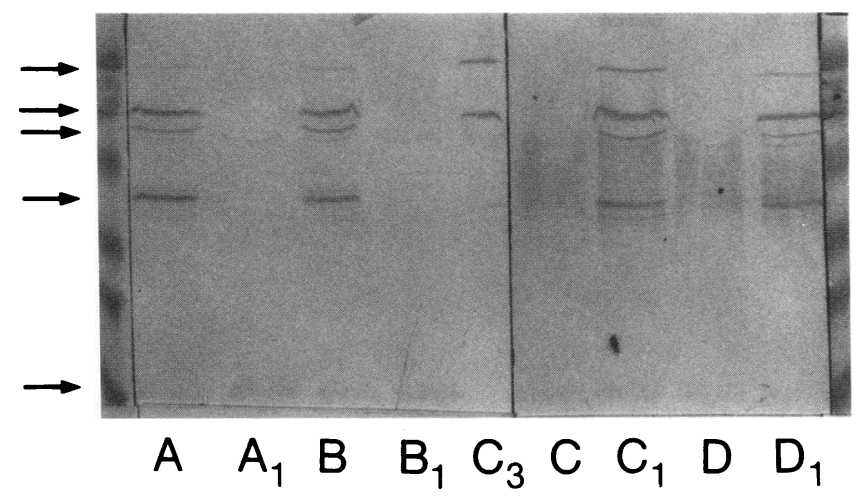

Figure 14. Molecular form of the bound C3 fragments. C3 deposition on Serratia \#21 and \#7 was done as outlined in the method in Table III except that the organisms were incubated with Hypo serum without added radioactive $\mathrm{C} 3$. The $\mathrm{C} 3$ fragments were eluted from the organisms by treating them with $1 \mathrm{M}$ hydroxylamine in $0.2 \mathrm{M}$ $\mathrm{NaHCO}_{3}$ containing $0.1 \%$ SDS (pH 10.0) for $60 \mathrm{~min}$ at $37^{\circ} \mathrm{C}$. The bacteria were removed by centrifugation, and the supernatant fluid containing the eluted fragments was evaluated under reducing conditions by SDS-PAGE with $10 \%$ polyacrylamide gels and transferred to nitrocellulose. The transblots were incubated in $1 \%$ casein for 30 min, followed by incubation in a 1:100 dilution in $1 \%$ casein of goat anti-human C3 linked to alkaline phosphatase and then were developed. Molecular weight markers are from top to bottom: $110 \mathrm{kD}, 84$ $\mathrm{kD}, 47 \mathrm{kD}, 33 \mathrm{kD}, 24 \mathrm{kD}$, and $16 \mathrm{kD}$. The serum used in these experiments was Hypo $\gamma$ serum (40\% final concentration in PBS). Lanes $A, A 1$, and $B, B 1$ represent Serratia \#21. Lanes $C, C 1$, and $D, D I$ represent Serratia \#7. Lane $C 3$ represents purified native complement component $C 3$. Lanes $A, B, C 1$, and $D 1$, represent organisms incubated in Hypor serum with normal complement activity. Lanes $A 1$, $B 1, C$, and $D$ represent bacteria incubated in control reaction mixtures containing heat-inactivated Hypo $\gamma$ serum. Samples $A, A 1, C$, $C l$ contain anti-Gal. Samples $B, B 1$, and $D, D l$ do not contain anti$\mathrm{Gal}$. The arrows point to the major fragments of $\mathrm{C} 3$ obtained. The $105-\mathrm{kD}$ chain in lanes $A, B, C l$, and $D I$ indicates the presence of $C 3 \mathrm{~b}$; the $67-\mathrm{kD}$ and $40-\mathrm{kD}$ chains in lanes $A, B, C 1$, and $D 1$ indicate $\mathrm{iC} 3 \mathrm{~b}$, and the $75-\mathrm{kD}$ band is the $\beta$ chain common to both $\mathrm{C} 3 \mathrm{~b}$ and $\mathrm{iC} 3 \mathrm{~b}$. The 16-kD band in all lanes may represent a fragment of $C 3 \mathrm{~d}$ (binds to anti-C3d; results not shown). Lanes $A 1, B 1, C$, and $D$ represent reaction mixtures with heat-inactivated sera and only show faint bands corresponding to $\mathrm{iC} 3 \mathrm{~b}$ and also show the 16-kD band. Lane $\mathrm{C} 3$ which represents control purified complement component $\mathrm{C} 3$ has two bands: one at $110 \mathrm{kD}$ representing the $\alpha$ chain of $\mathrm{C} 3$ and one at $75 \mathrm{kD}$ representing the $\beta$ chain of $\mathrm{C} 3$. Note that anti-Gal has no effect on the fragmentation pattern of C3b on both Serratia \#21 and \#7 (compare lane $A$ to lane $B$ for strain \#21 and lane $C 1$ to lane $D 1$ for strain \#7). This experiment has been repeated four times with identical results obtained in all four. This blot is representative of the results obtained.

The experiment represented by Fig. 14 has been done four times and identical results were obtained in all four. Fig. 14 is a representative blot.

C9 deposition on Serratia \#21 in the presence and absence of anti-Gal. Fig. 15 reveals that C9 is deposited onto Serratia \#21 whole organism when incubated with hypor serum alone or with hypor serum with anti-Gal. No C9 is deposited when the serum is heat-inactivated (hatched bars). This experiment shows that anti-Gal does not inhibit the deposition of $\mathrm{C} 9$ onto Serratia \#21 even though this antibody blocks the killing of Serratia $\# 21$. 


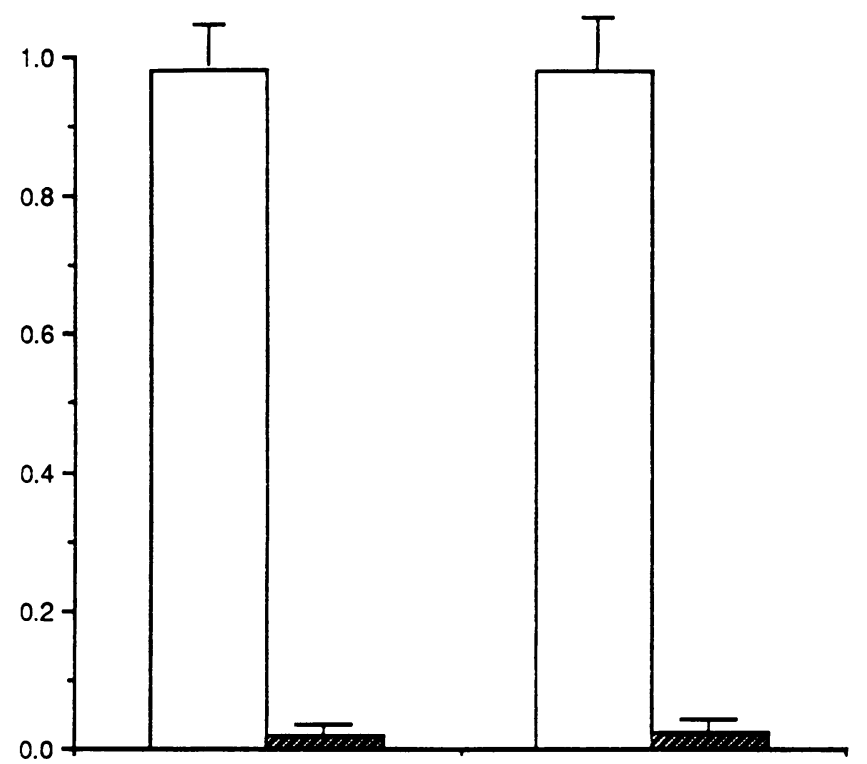

Hypor

Hypo + anti-Gal

Figure 15. Deposition of C9 on Serratia \#21, as demonstrated by ELISA. Serratia \#21 was either presensitized with anti-Gal and then incubated in Hypo $\gamma$ serum (right) or only incubated in Hypo $\gamma$ serum without presensitization with anti-Gal (left). The bacteria were then washed and assayed for associated C9 in a whole cell ELISA that used goat anti-human C9 linked to alkaline phosphatase to detect bound C9. Data are from one representative experiment and show the mean \pm SD of the absorbance $(405 \mathrm{~nm})$ for triplicate measurements. Open bars represents serum with normal complement activity. Hatched bars represent reactions with heat-inactivated serum. Note that equivalent amounts of $\mathrm{C} 9$ are deposited on Serratia $\# 21$ by hypor serum in the presence and in the absence of anti-Gal.
MAC formation on Serratia \#21 by hypo sera in the presence and absence of anti-Gal. Fig. 16 shows representative electron micrographs of Serratia \#21 incubated with hypo $\gamma$ serum with anti-Gal $(A)$ or heat-inactivated hypor serum with antiGal $(B)$. Identical binding patterns were obtained with organisms not presensitized with anti-Gal (results not shown). MAC was deposited onto Serratia \#21 in the presence of anti-Gal (Fig. 16 A) despite the fact that this antibody completely blocks the complement-mediated killing of this strain. Note that there is very low nonspecific binding of the monoclonal antibody (recognizing the MAC neoantigen) to Serratia \#21 when the organism is incubated in heat-inactivated serum (Fig. $16 \mathrm{~B}$ ).

Anti-Gal therefore does not inhibit the assembly of a MAC on the surface of Serratia \#21, even though anti-Gal blocks the complement-mediated lysis of this strain.

\section{Discussion}

The findings we report here challenge the traditional role of antibody, that of a molecule that protects the host from bacterial invasion. The human anti-Gal IgG, a ubiquitous high titered natural antibody, does not appear to provide a protected site for $\mathrm{C} 3$ deposition, nor does it initiate immune lysis. It can in fact block ACP-mediated lysis when it finds its epitope on the lipopolysaccharide of Serratia \#21.

That anti-Gal may play a role in the pathogenesis of Gramnegative sepsis is suggested by the fact that this antibody binds significantly more often to Enterobacteriaceae isolated from the blood of patients with sepsis than to Enterobacteriaceae recovered from the stool of healthy laboratory volunteers. Because these volunteers work in a hospital setting, their stool flora may be more representative of hospital flora than street
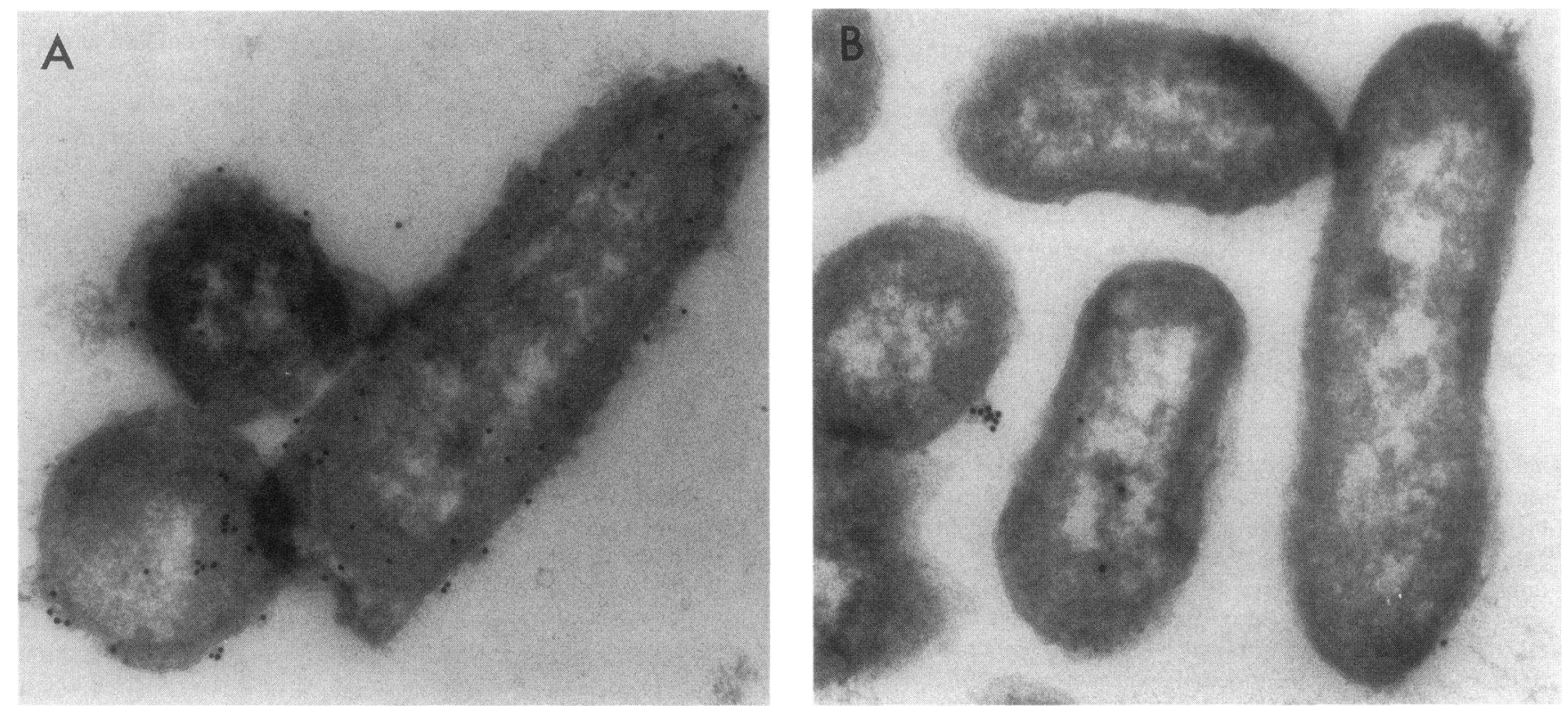

Figure 16. Detection of the MAC on Serratia \#21 by electron microscopy. Sectioned organisms were presensitized with anti-Gal (100 $\mu \mathrm{g} / \mathrm{ml})$ for 30 min and then incubated for $1 \mathrm{~h}$ with $20 \%$ Hypo $\gamma$ serum (Panel $A, \times 50,000)$ or with heat-inactivated Hypo $\gamma$ serum $($ Panel $B, \times 37,000)$. The organism was then reacted with a monoclonal anti-human C5b-9 and then with goat anti-mouse IgG conjugated to gopld (15 nm). The monoclonal antibody used binds to a neoantigen on the C5b-9 complex (MAC) of human complement. Note that this monoclonal antibody binds to Serratia \#21 in the presence of anti-Gal, indicating that a MAC was formed on the surface of the bacteria under these conditions. 
flora. The difference we found between the stool's and the blood isolates' prevalence of binding to anti-Gal therefore might be even more pronounced if we had studied individuals that work in the community. The ability of Escherichia coli to bind anti-Gal seems to be a necessary but insufficient attribute for sepsis to occur; binding of anti-Gal by other enteric organisms also seems to enhance their ability to cause sepsis.

If binding of anti-Gal is an important factor in the pathogenesis of sepsis, then anti-Gal must interfere with normal host defense mechanisms. We chose to examine the effect of antiGal on a complement-mediated clearance mechanism, immune lysis, since blocking of immune lysis by IgG (31) had been described previously. Unlike other serum IgG antibodies, anti-Gal does not activate the classical complement pathway when it binds the bacteria we studied, and its effect appears to be exclusively on the ACP. It seems reasonable to assume, then, that anti-Gal plays an immunopathogenic role mostly in the "nonimmune" host that has not synthesized other specific antibodies.

Specific blocking antibodies have been found before in NHS $(31,32)$; however, these earlier studies did not define the specificity of the blocking IgG nor did they examine the complement pathway that was involved. When we examined the effect of anti-Gal on two representative $S$. marcescens human isolates, we found that anti-Gal did not increase the number of C3 molecules deposited by the ACP in hypogammaglobulinemic serum, nor did it change the degradation pattern of the covalently bound $\mathrm{C} 3 \mathrm{~b}$ fragments on these organisms. We therefore would not have expected anti-Gal to modulate ACP-mediated immune effector mechanisms on these two Serratia, and that appeared consistent with its modest enhancement of ACP lysis of a Ser Serratia, \#7, which also bound other IgG in NHS. Anti-Gal, however, had a major effect on the ACP-mediated lysis of Ser' Serratia, \#21, which did not bind any other IgG to its LPS. Anti-Gal completely blocked the ability of serum to kill this organism and was solely responsible for the normal serum resistance of the bacteria.

The mechanism of blockade by anti-Gal remains unclear. It did not change the number of molecules of $\mathrm{C} 3$ deposited onto Serratia $\# 21$. Approximately 13,000 molecules of C3 were deposited specifically on Serratia $\# 21$ by hypo $\gamma$ serum, both in the presence and absence of anti-Gal. Wright et al. (33) showed that only two terminal membrane attack complexes were sufficient to cause disruption of both the inner and outer membranes of $E$. coli, so the number of $\mathrm{C} 3$ molecules deposited onto Serratia \#21 should have been more than enough to support lysis unless they completely failed to assemble membrane attack complexes.

The number of C 3 molecules deposited on Serratia \#21 and \#7 by heat-inactivated $\mathrm{Gal}^{-}$and Hypo $\gamma$ sera differed for each organism and was much higher in $\Delta \mathrm{Gal}^{-}$than in $\Delta \mathrm{Hy}-$ po $\gamma$ sera, for reasons that are unclear to us at this point. The somewhat higher than reported percent of $\mathrm{C} 3$ molecules deposited in heat-inactivated sera in our experiments $(30 \%$ of total C3 deposited compared to 10-20\% in the literature) may have obscured small but important differences between $\mathrm{C} 3$ binding in the presence and absence of anti-Gal. However, the $\mathrm{C} 3$ molecules deposited onto Serratia $\# 21$ by hypo $\gamma$ serum resulted in partial killing of the bacteria, showing that they were able to initiate lysis in the absence of anti-Gal, but they were completely ineffective in the presence of this antibody. This was not because anti-Gal changed the site of binding of C3 (LPS) or the molecular form of its fragments on Serratia \#21 (mostly iC 3b, but also a fragment of C3d and minor amounts of $\mathrm{C} 3 \mathrm{~b}$ ). Nor did anti-Gal inhibit C9 deposition or MAC formation on the organism.

It remains possible that anti-Gal may be "relocating" the MAC to a nonlytic site on the LPS of Serratia $\# 21$, perhaps by occupying the "preferred" site of C3b binding. This would imply that the many $\mathrm{OH}$ residues that are available on this LPS are not equivalent in their influence on the subsequent generation of an "effective" MAC by C3b molecules that bind to them. Another possibility would be that anti-Gal may affect the stability of the MAC on the surface of the organism, perhaps by occluding the insertional site of the MAC. Ineffective deposition of the C5b-9 complex in the presence of specific antibody had been reported for serum resistant strains of $\mathrm{Sal}$ monella minnesota $(34,35)$ and Neisseria gonorrhoeae $(36)$. However, the role, if any, of the antibody in NHS in the ineffective deposition of the MAC onto these bacteria was not investigated and neither was the complement pathway through which these bacteria were killed.

The two Serratia also differed in the sites to which they bound anti-Gal. This could have been because they bound different populations of anti-Gal. Methyl $\alpha$-galactoside, but not lactose or sucrose, inhibited the blocking of ACP killing of strain \#21 by anti-Gal, showing that the specificity of anti-Gal on strain \#21 was, as expected, for a structure similar to methyl $\alpha$-galactoside. There is, however, a considerable diversity in the recognition of $\alpha$-linked galactose epitopes by human natural antibodies; $\alpha 1,3, \alpha 1,2, \alpha 1,4$, and $\alpha 1,6$ antibody specificities have all been described (37). The highest affinity of anti-Gal is for galactose $\alpha 1,3$ galactose; its affinity decreases when it binds galactose $\alpha$-linked to other carbons in the order of $\alpha 1,2$, then $\alpha$ 1,6 , and then the almost inactive $\alpha 1,4$ bond (37). The fact that absorbing anti-Gal with either Serratia abolished its binding to the other shows that the two strains do share antigenic specificities for anti-Gal. The antibody found its antigen within different carbohydrate organelles, however, implying that there are differences in the chemical structures that flank the anti-Gal binding sites. The acidic nature of most $\mathrm{K}$ antigens made by Enterobacteriaeceae and the neutral nature of their LPS (38) would provide for such a difference. Defining the exact structures of anti-Gal binding sites on strains \#21 and \#7 should provide information about the chemical nature of bacterial $\mathrm{ACP}$ regulatory sites.

The anti-Gal that bound LPS could have been of an isotype that has little complement activating potential, whereas that which bound capsular polysaccharide could have been of a different isotype. Human anti-Gal is composed of all IgG subclasses with IgG2 > IgG1 > IgG3 > IgG4 (39), so this seems an unlikely explanation and we did not pursue it.

Serratia \#21 had mostly iC $3 \mathrm{~b}$ and only minor amounts of C3b on its surface when incubated in hypo $\gamma$ serum, and yet was partially lysed. The more sensitive Serratia \#7 incubated in hypo $\gamma$ serum deposited mostly $\mathrm{C} 3 \mathrm{~b}$ and iC $3 \mathrm{~b}$ onto its surface. Both strains also bound a fragment of C3d. The addition of anti-Gal had no effect on the C3b degradation patterns on either Serratia. This emphasizes that anti-Gal does not provide an antibody-facilitated site for $\mathrm{C} 3$ activation.

Why some $\mathrm{C} 3 \mathrm{~b}$ molecules are degraded to $\mathrm{iC} 3 \mathrm{~b}$, whereas others are further degraded to C3d, is not entirely clear. C3d binds $\mathrm{CR} 2$ in $\mathrm{B}$ lymphocyte membranes and initiates an antibody response (40). Different pneumococcal capsular polysac- 
charides bind different amounts of C3d, and these differences are related to differences in their immunogenicity (41). Serotypes that are highly immunogenic in man have abundant C3d on their surfaces; less immunogenic serotypes do not (42). This would seem to indicate that the fate of bound $\mathrm{C} 3 \mathrm{~b}$ may depend upon the exact nature of the $\mathrm{OH}$ radical to which its $\mathrm{C} 3 \mathrm{~d}$ domain has bound.

A low $M_{\mathrm{r}}$ fragment of $\mathrm{C} 3 \mathrm{~b}(16,000)$ that may represent a fragment of C3d was eluted from Serratia \#21 that had been incubated in hypor serum. It would be interesting to learn whether this fragment can bind CR2 and promote further production of blocking anti-Gal, thereby perpetuating the organism's evasion of host defense mechanisms.

The major C3b degradation product on Serratia \#21, when incubated with or without anti-Gal, was iC3b which can bind CR3 receptors on phagocytes. Studies that examine the effect of anti-Gal on opsonophagocytosis of Serratia \#21 by polymorphonuclear leukocytes are in progress; they should clarify whether this antibody can also interfere with this immune effector mechanism.

A dual role as both agonist and antagonist of complement activation on bacterial surfaces has been reported previously for IgG and IgA molecules of different specificities (27, 36, 43, 44). How and when an Ig molecule plays a blocking rather than a permissive role is not understood. Our data suggest that it may be largely a function of where the antibody binds on the bacterial outer membrane.

Anti-Gal participates in the clearance of senescent or pathologically deformed erythrocytes that surface expose cryptic galactosyl structures $(45,46)$. Anti-Gal's blocking of ACP activation may serve to protect man from continuous activation of complement on the surface of these and potentially other senescent human cells. Conversely, anti-Gal appears to play a detrimental role in the pathogenesis of certain autoimmune disorders, including thyroiditis, IgA nephropathy, and HenochShoenlein purpura $(16,47)$. Our findings suggest that anti-Gal also may play a role in the intravascular survival of certain Gram-negative bacteria and raise intriguing questions about the effect of this ubiquitous molecule on other immune effector mechanisms, including opsonophagocytosis and $\mathrm{T}$ and $\mathrm{B}$ cellmediated events.

\section{Acknowledgments}

We thank Teresa Chiu for expert technical assistance.

This work was supported in part by the Veterans Administration and Public Health Service grant AI 21171 (J. McLeod Griffiss) from the National Institutes of Health.

\section{References}

1. Galili, U., E. A. Rachmilewitz, A. Peleg, and I. Flechner. 1984. A unique natural human IgG antibody with anti- $\alpha$ galactosyl specificity. J. Exp. Med. 160:1519-1531.

2. Galili, U., B. A. Macher, J. Buehler, and S. B. Shohet. 1985. Human natural anti- $\alpha$-galactosyl IgG. II. The specific recognition of $\alpha 1,3$-linked galactose residues. J. Exp. Med. 162:573-582.

3. Spiro, R. G., and V. D. Bhoyroo. 1984. Occurence of $\alpha$-D-galactosyl residues in the thyroglobulins from several different species. J. Biol. Chem. 259:9858-9866.

4. Newman, G. R., B. Jasani, E. D. Williams, A. E. Eckhardt, and I. J. Goldstein. 1983. Isolation and characterization of a family of $\alpha$-D-galactosyl containing glycopeptides from Ehrich ascites tumor cells. Biochemistry. 22:5290-5297.

5. Cummings, R. D., and S. A. Mattox. 1988. Retinoic acid-induced differen- tiation of the mouse teratocarcinoma cell line F9 is accompanied by an increase in the activity of UDP-galactose: $\beta$-D-galactosyl- $\alpha 1,3$-galactosyltransferase. $J$. Biol. Chem. 263:511-519.

6. Eto, T., Y. Iichikawa, K. Nishimura, S. Ando, and T. Yamakawa. 1968. Chemistry of lipids of the posthemolytic residue or stroma of erythrocytes. XVI. Occurrence of ceramide pentasaccharide in the membrane of erythrocytes and reticulocytes in rabbit. J. Biochem. (Tokyo). 64:205-213.

7. Uemura, K., M. Yuzawa, and T. Taketomi. 1978. Characterization of the major glycolipids in bovine erythrocyte membrane. J. Biochem. (Tokyo). 83:463471.

8. Galili, U., M. R. Clark, S. B. Shohet, J. Bueller, and B. A. Macher. 1987. Evolutionary relationship between the natural anti-Gal antibody and the Gal $\alpha$ 1,3 Gal epitope in primates. Proc. Natl. Acad. Sci. USA. 84:1369-1373.

9. Galili, U., S. B. Shohet, E. Kobrin, C. L. M. Stults, and B. A. Macher. 1988. Man, apes, and Old World monkeys differ from other mammals in the expression of $\alpha$-galactosyl epitopes on nucleated cells. J. Biol. Chem. 263:17755-17762.

10. Wiener, A. S. 1951. Origin of naturally occuring hemagglutinins and hemolysins. J. Immunol. 66:287-295.

11. Galili, U., R. E. Mandrell, R. M. Hamadeh, S. B. Shohet, and J. McL. Griffiss. 1988. The interaction between human natural anti- $\alpha$-galactosyl IgG (anti-Gal) and bacteria of the human flora. Infect. Immun. 56:1730-1737.

12. Hamadeh, R. M., R. E. Mandrell, and J. McL. Griffiss. 1990. Immunophysical characterization of human isolates of Serratia marcescens. J. Clin. Microbiol. 28:20-26.

13. Westphal, O., and K. Jann. 1965. Bacterial lipopolysaccharides. Extraction with phenol-water and further applications of the procedure. In Methods in Carbohydrate Chemistry. Vol. 5. Academic Press, New York. 83-91.

14. Zollinger, W. D., and R. E. Mandrell. 1977. Outer membrane protein and lipopolysaccharide serotyping of Neisseria meningitidis by inhibition of a solid phase radioimmunoassay. Infect. Immun. 18:424-433.

15. Galili, U., J. Buehler, S. B. Shohet, and B. A. Macher. 1987. The human natural anti-Gal IgG. III. The subtlety of immune tolerance in man as demonstrated by cross-reactivity between natural anti-Gal and anti-B antibodies. J. Exp. Med. 165:693-704.

16. Etienne-Decerf, J., M. Malaise, P. Mahieu, and R. Winand. 1987. Elevated anti- $\alpha$-galactosyl antibody titers. A marker of progression in autoimmune thyroid disorders and in endocrine ophthalmopathy? Acta Endocrinol. 115:6774.

17. Platts-Mills, T. A. E., and K. Ishizaka. 1974. Activation of the alternate pathway of human complement by rabbit red cells. J. Immunol. 113:348-358.

18. Kim, J. J., R. E. Mandrell, and J. McL. Griffiss. 1989. Neisseria lactamica and Neisseria meningitidis share lipooligosaccharide epitopes, but lack common capsular and class 1, 2, and 3 protein epitopes. Infect. Immun. 57:602-608.

19. Zollinger, W. D., B. L. Brandt, E. C. Tramont, and A. S. Dobek. 1980. Immune response to Neisseria meningitidis. In Manual of Clinical Immunology, 2nd ed. N. R. Rose and H. Freidman, editors. American Society for Microbiology, Washington, DC. 446-453.

20. Densen, P., J. M. Weiler, J. McL. Griffiss, and L. J. Hoffman. 1987. Familial properdin deficiency and fatal meningococcemia. N. Engl. J. Med. 316:922-926.

21. Thorell, J. I., and I. Larson. 1974. Lactoperoxidase coupled to polyacrylamide for radio-iodination of proteins to high specific activity. Immunochemistry. 11:203-206.

22. Hitchcock, P. J., and T. M. Brown. 1983. Morphological heterogeneity among Salmonella lipopolysaccharide chemotypes in silver-stained polyacrylamide gels. J. Bacteriol. 154:269-277.

23. Laemmli, U. K. 1970. Cleavage of structural proteins during assembly of the head of bacteriophage T4. Nature (Lond.). 227:680-685.

24. Burnette, W. N. 1981. "Western blotting": electrophoretic transfer of proteins from sodium dodecyl sulfate-polyacrylamide gels to unmodified nitrocellulose and radiographic detection antibody and radioiodinated protein $A$ Anal. Biochem. 112:195-203.

25. Thall, A., and U. Galili. 1990. Distribution of Gal $\alpha 1,3 \mathrm{Gal} \beta 1,4 \mathrm{GlcNAc}$ residues on secreted mammalian glycoproteins (thyroglobulin, fibrinogen, and immunoglobulin G) as measured by a sensitive solid-phase radioimmunoassay. Biochemistry. 29:3959-3965.

26. Hammer, C. H., G. H. Wirtz, L. Renfer, H. D. Gresham, and B. F. Tack. 1981. Large scale isolation of functionally active components of the human complement system. J. Biol. Chem. 256:3995-4006.

27. Jarvis, G. A., and J. McL. Griffiss. 1989. Human IgA1 initiates complement-mediated killing of Neisseria meningitidis. J. Immunol. 143:1703-1709.

28. Hostetter, M. K., R. A. Krueger, and D. Y. Schmeling. 1984. The biochemistry of opsonization: central role of the reactive thiolester of the third component of complement. J. Infect. Dis. 150:653-661.

29. Kozel, T. R., M. A. Wilson, T. P. Farrell, and S. M. Levitz. 1989. Activation of C3 and binding to Aspergillus fumigatus conidia and hyphae. Infect. Immun. 57:3412-3417.

29a. Schlesinger, L. S., C. G. Bellinger-Kawahara, N. R. Payne, and M. A. 
Horwitz. 1990. Phagocytosis of Mycobacterium tuberculosis is mediated by human monocyte complement receptors and complement component C3. J. Immunol. 144:2771-2780.

30. Schneider, H., C. A. Hammack, M. A. Apicella, and J. McL. Griffiss. 1988. Instability of expression of lipooligosaccharides and their epitopes in Neisseria gonorrhoeae. Infect. Immun. 56:942-946.

31. Guttman, R. M., and B. A. Waisbren. 1975. Bacterial blocking activity of specific IgG in chronic Pseudomonas aeruginosa infection. Clin. Exp. Immunol. 19:121-130.

32. Waisbren, B. A., and I. Brown. 1966. A factor in serum of patients with persisting infection that inhibits the bactericidal activity of normal serum against the organism that is causing the infection. J. Immunol. 97:431-437.

33. Wright, S. D., and R. P. Levine. 1981. How complement kills $E$. coli. II. The apparent two-hit nature of the lethal event. J. Immunol. 127:1152-1156.

34. Joiner, K. A., C. H. Hammer, E. J. Brown, R. J. Cole, and M. M. Frank. 1982. Studies on the mechanism of bacterial resistance to complement-mediated killing I. Terminal complement components are deposited and released from Salmonella minnesota $\mathbf{S 2 1 8}$ without causing bacterial death. J. Exp. Med. 55:797-808.

35. Joiner, K. A., C. H. Hammer, E. J. Brown, and M. M. Frank. 1982. Studies on the mechanism of bacterial resistance to complement-mediated killing. II. C8 and C9 release C5b67 from the surface of Salmonella minnesota S218 because the terminal complex does not insert into the bacterial outer membrane. J. Exp. Med. 155:809-819.

36. Joiner, K. A., K. A. Warren, E. J. Brown, J. Swanson, and M. M. Frank. 1983. Studies on the mechanism of bacterial resistance to complement-mediated killing. IV. C5b-9 forms high molecular weight complexes with bacterial outer membrane constituents on serum-resistant but not on serum-sensitive Neisseria gonorrhoeae. J. Immunol. 131:1443-1451.

37. Wieslander, J., O. Mansson, E. Kallin, A. Gabrielli, H. Nowack, and R. Timpl. 1990. Specificity of human antibodies against gal $\alpha 1$-3gal carbohydrate epitope and distinction from natural antibodies reacting with gal-2gal or gal-4gal. Glycoconjugate J. 7:85-100.
38. Jann, K., and B. Jann. 1984. Structure and biosynthesis of O-antigens. In Handbook of Endotoxin. Vol. 1. Chemistry of Endotoxin. E. T. Rietschel, editor. Elsevier Science Publishers B. V., Amsterdam. 138-186.

39. Ravindran, B., A. K. Satapathy, and M. K. Das. 1988. Naturally-occurring anti- $\alpha$-galactosyl antibodies in human plasmodium falciparum infectionsa possible role for autoantibodies in malaria. Immunol. Lett. 19:137-142.

40. Feldman, M., and M. B. Pepys. 1974. Role of C3 in in vitro lymphocyte cooperation. Nature (Lond.). 249:159-161.

41. Gordon, D. L., J. Rice, J. J. Finlay-Jones, P. J. McDonald, and M. K. Hostetter. 1988. Analysis of $\mathrm{C} 3$ deposition and degradation on bacterial surfaces after opsonization. J. Infect. Dis. 157:697-704.

42. Hostetter, M. K. 1986. Serotypic variation among virulent pneumococci in deposition and degradation of covalently bound $\mathrm{C} 3 \mathrm{~b}$ :implications for phagocytosis and antibody production. J. Infect. Dis. 153:682-693.

43. Rice, P. A., H. E. Vayo, M. R. Tam, and M. S. Blake. 1986. Immunoglobulin $\mathbf{G}$ antibodies directed against protein III block killing of serum resistant Neisseria gonorrhoeae by immune serum. J. Exp. Med. 164:1735-1748.

44. Joiner, K. A., R. Scales, K. A. Warren, M. M. Frank, and P. A. Rice. 1985. Mechanism of action of blocking immunoglobulin G for Neisseria gonorrhoeae. J. Clin. Invest. 76:1765-1772.

45. Galili, U., I. Flechner, A. Knyszynski, D. Danon, and E. A. Rachmilewitz. 1986. The natural anti- $\alpha$-galactosyl IgG on human normal senescent red blood cells. Br. J. Haematol. 62:1-4.

46. Galili, U., M. R. Clark, and S. B. Shohet. 1986. Excessive binding of natural anti-alpha-galactosyl immunoglobulin $\mathrm{G}$ to sickle erythrocytes may contribute to extravascular cell destruction. J. Clin. Invest. 77:27-33.

47. Towbin, H., G. Rosenfelder, J. Wieslander, J. L. Avila, M. Rojas, A. Szarfman, K. Esser, H. Nowack, and R. Timpl. 1987. Circulating antibodies to mouse laminin in Chaga's disease, American cutaneous Leishmaniasis, and normal individuals recognize terminal galactosyl $(\alpha 1,3)$-galactose epitopes. J. Exp. Med. 166:419-432. 